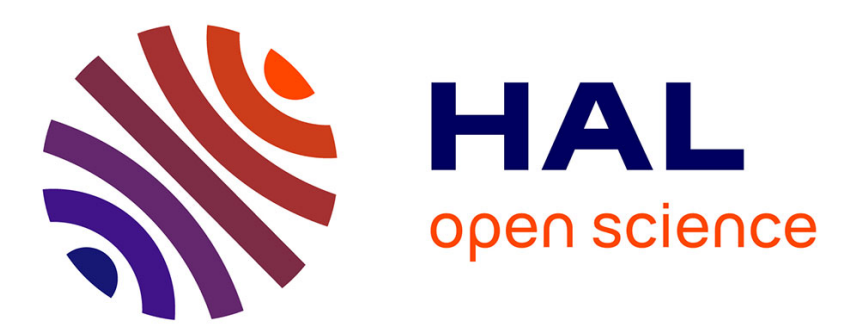

\title{
Nitric oxide production mediates oligogalacturonide-triggered immunity and resistance to Botrytis cinerea in Arabidopsis thaliana
}

Sumaira Rasul, Carole Dubreuil, Olivier Lamotte, Emmanuel Koen, Benoît

Poinssot, Gérard Alcaraz, David Wendehenne, Sylvain Jeandroz

\section{To cite this version:}

Sumaira Rasul, Carole Dubreuil, Olivier Lamotte, Emmanuel Koen, Benoît Poinssot, et al.. Nitric oxide production mediates oligogalacturonide-triggered immunity and resistance to Botrytis cinerea in Arabidopsis thaliana. Plant, Cell and Environment, 2012, 35 (8), pp.1483-1499. 10.1111/j.13653040.2012.02505.x . hal-01137174

\section{HAL Id: hal-01137174 \\ https://hal.science/hal-01137174}

Submitted on 30 Mar 2015

HAL is a multi-disciplinary open access archive for the deposit and dissemination of scientific research documents, whether they are published or not. The documents may come from teaching and research institutions in France or abroad, or from public or private research centers.
L'archive ouverte pluridisciplinaire HAL, est destinée au dépôt et à la diffusion de documents scientifiques de niveau recherche, publiés ou non, émanant des établissements d'enseignement et de recherche français ou étrangers, des laboratoires publics ou privés. 


\title{
Nitric oxide production mediates oligogalacturonide- triggered immunity and resistance to Botrytis cinerea in Arabidopsis thaliana
}

\author{
S. RASUL ${ }^{1,2,3}$, C. DUBREUIL-MAURIZI ${ }^{2,3}$, O. LAMOTTE ${ }^{3,4}$, E. KOEN ${ }^{2,3}$, B. POINSSOT ${ }^{2,3}$, G. ALCARAZ ${ }^{1,3}$, \\ D. WENDEHENNE ${ }^{2,3} \&$ S. JEANDROZ ${ }^{1,3}$ \\ ${ }^{1}$ AgroSup, UMR 1347 Agroécologie, BP 86510, ${ }^{2}$ Université de Bourgogne, UMR 1347 Agroécologie, BP 86510, ${ }^{3}$ ERL CNRS \\ 6300, BP 86510 and ${ }^{4}$ CNRS, UMR 1347 Agroécologie, BP 86510, F-21000 Dijon, France
}

\begin{abstract}
Nitric oxide (NO) regulates a wide range of plant processes from development to environmental adaptation. In this study, we investigated the production and/or function of NO in Arabidopsis thaliana leaf discs and plants elicited by oligogalacturonides (OGs) and challenged with Botrytis cinerea. We provided evidence that $O$ Gs triggered a fast and long lasting NO production which was $\mathrm{Ca}^{2+}$ dependent and involved nitrate reductase (NR). Accordingly, OGs triggered an increase of both NR activity and transcript accumulation. NO production was also sensitive to the mammalian NO synthase inhibitor L-NAME. Intriguingly, we showed that L-NAME affected NO production by interfering with NR activity, thus questioning the mechanisms of how this compound impairs NO synthesis in plants. We further demonstrated that NO modulates RBOHDmediated reactive oxygen species (ROS) production and participates in the regulation of OG-responsive genes such as anionic peroxidase (PER4) and a $\beta$-1,3-glucanase. Mutant plants impaired in PER4 and $\beta$-1,3-glucanase, as well as Col-0 plants treated with the NO scavenger cPTIO, were more susceptible to $B$. cinerea. Taken together, our investigation deciphers part of the mechanisms linking NO production, NO-induced effects and basal resistance to B. cinerea.
\end{abstract}

Keywords: calcium; nitrate reductase; plant defence; reactive oxygen species.

\section{INTRODUCTION}

Defence responses of plants against microbial attack are initiated by signal molecules released during the infection process and mediated by a number of signalling components. These components include nitric oxide (NO), a widespread molecule in living organisms involved in major physiological processes (Torreilles 2001; Besson-Bard,

Correspondence: S. Jeandroz.E-mail: s.jeandroz@agrosupdijon.fr
Pugin \& Wendehenne 2008a). In mammals, NO is mainly synthesized from L-arginine by NO synthase (NOS). In plants, NO is also derived from nitrogen-containing precursors but these precursors are more diverse than in animals. In broad outline, NO is thought to be generated in plants from two enzymatic pathways: an L-arginine-dependent pathway and a nitrite-dependent pathway (Besson-Bard et al. 2008a). Many studies highlighted the occurrence of an enzymatic process in which NO is produced from L-arginine by an unidentified enzyme sensitive to mammalian NOS inhibitors (also named NOS-like enzyme) although there is no obvious homolog of mammalian NOS in the plant genomes sequenced so far (Cueto et al. 1996; Modolo et al. 2002; del Río et al. 2004; Corpas et al. 2006). Tun et al. (2008) have reported the putative involvement of a polyamine (PA)-dependent production of NO related to L-arginine metabolism, this amino acid being one key precursor of PAs. In vivo and in vitro studies also highlighted that NO is a by-product of nitrate reductase (NR) activity when nitrite is used as a substrate (Yamasaki 2000; Sakihama, Nakamura \& Yamasaki 2002). NO production from NR occurs in specific context in which the cytosolic nitrite reaches high concentrations, that is in the $\mathrm{mm}$ range. NR was shown to be involved in NO production in several physiological situations, such as abscisic acid (ABA)induced stomatal closure, hypoxia, cold stress or in nitrogen-fixing nodules (Desikan et al. 2002; Dordas et al. 2004; Zhao et al. 2009; Cantrel et al. 2011; Horchani et al. 2011). In Arabidopsis thaliana, two cytosolic isoforms of NR (NR1 and NR2) have been identified. These isoforms have a high degree of coding sequence similarity and are $83.5 \%$ identical at the amino acid level. NR2 represents $\sim 90 \%$ of the total NR activity regarding nitrate reduction (Wilkinson \& Crawford 1991). Comparative analysis using the single mutants nia1 and nia2 suggested that the most committed $\mathrm{NR}$ isoform to $\mathrm{NO}$ production in response to ABA or cold stress was encoded by NRI (Bright et al. 2006; Zhao et al. 2009). Finally, it has also been reported that NO synthesis from nitrite occurs in mitochondria associated with mitochondrial electron transport (Planchet et al. 2005; Horchani et al. 2011). 
In plants, NO was found, among different roles, to be involved in mediating defence reactions against microbial pathogens (Delledonne et al. 1998; Leitner et al. 2009). Firstly, NO was reported to be rapidly generated in several plant-pathogen models and using different detection methods (Vandelle \& Delledonne 2008). A rapid and intense intracellular NO production was detected in tobacco epidermal cells and cell suspensions treated with the Phytophthora cryptogea elicitin cryptogein using diaminofluorescein diacetate (DAF-2DA), a cell permeable NO specific fluorescent probe (Foissner et al. 2000) and by electrochemistry (Besson-Bard et al. 2008b). In response to the necrotrophic fungus Botrytis cinerea, Pelargonium peltatum leaves also initiated a near-immediate NO burst but, interestingly, its generation was dependent on the genetic make-up of the host plant. Precisely, in resistant genotypes, a subsequent wave of NO generation was correlated with the resistance to $B$. cinerea, whereas in susceptible cultivar, the second NO burst was absent (Floryszak Wieczorek et al. 2007). Recently, Piterkova et al. (2009) also reported a systemic NO production in adjacent and distant uninoculated leaves of tomato plants challenged with the biotrophic fungus Oidium neolycopersici. Secondly, it was shown that pathogen-induced NO production or exogenous treatment with NO donors affects plant defence molecular responses, such as the expression of defence-related genes or phytoalexins biosynthesis and, therefore, could participate in plant disease resistance (Delledonne et al. 1998; Durner, Wendehenne \& Klessig 1998). More recently, it was observed that the NRdeficient double mutant (nialnia2), which shows substantially reduced NO production after bacterial or fungal pathogen inoculation, showed no hypersensitive response and was hypersusceptible to Pseudomonas syringae (Modolo et al. 2006; Oliveira etal. 2009) and to the necrotrophic fungal pathogen Sclerotinia sclerotiorum (Perchepied et al. 2010). Although Modolo et al. (2006) have noticed that the levels of amino acids, and particularly L-arginine, are strongly reduced in nialnia2 $A$. thaliana leaves, NO emission by nialnia2 leaves did not increase in the amino acid-recovered mutants (Oliveira et al. 2009). These results suggest that the susceptibility to pathogen is a consequence of the reduced ability to synthesize NO. Similarly, plants affected in AtNOA1 (NOassociated protein 1) expression exhibited a reduced endogenous NO level and were more susceptible to the virulent bacteria P. syringae pv tomato DC3000, to the fungi Colletotrichum orbiculare, S. sclerotiorum and B. cinerea (Zeidler et al. 2004; Asai, Ohta \& Yoshioka 2008; Asai \& Yoshioka 2009; Perchepied et al. 2010).

Research conducted over the past years has revealed that NO mediates part of its effect through modulation of protein kinase activities, post-translational modifications of target proteins, and mobilization of free $\mathrm{Ca}^{2+}$ and other second messengers (Besson-Bard et al. 2008a). Particularly, it has been reported that the involvement of NO in plant immunity is related to its interplay with reactive oxygen species (ROS) and cell death occurring during hypersensitive response (HR) might result from the simultaneous and balanced production of NO and ROS (Zaninotto et al. 2006). NO and ROS exert reciprocal control on each other, directly (reaction of NO and ROS to form peroxynitrite anion $\mathrm{ONOO}^{-}$; Cecconi et al. 2009) or indirectly (e.g. through the NO-dependent inhibition of catalase and ascorbate peroxidase, two major $\mathrm{H}_{2} \mathrm{O}_{2}$-scavenging enzymes by NO; Clarke et al. 2000; Arasimowicz et al. 2009).

In spite of these numerous evidence providing indirect evidence associating NO to plant defence reactions, little is known about the mechanisms that link NO production to its physiological activity. In order to further investigate the role of $\mathrm{NO}$ in a pathophysiological context, in the present study we analysed its functions in the plant defence responses triggered by oligogalacturonides (OGs) in A. thaliana plants. OGs are structural components of the pectin homogalacturonan chains of plant cell wall. In A. thaliana, they are released during the interaction with pathogens, such as the necrotrophic fungus B. cinerea, which secretes polygalacturonase (PG) as part of their cell wall degrading enzyme arsenal. OGs, with a degree of polymerization (DP) between 10 and 25, are considered as endogenous elicitors as they are released from plant cell wall in response to the damage caused by invading pathogens. In A. thaliana or grapevine (Vitis vinifera), OG treatment induces a variety of defence responses including accumulation of phytoalexins, $\beta$-1,3-glucanase and chitinase. Moreover, OGs have been shown to contribute to triggered immunity against fungal pathogens including B. cinerea (Aziz et al. 2007; Ferrari et al. 2007). About half of the $A$. thaliana genes affected by OG treatment display a similar pattern of expression after B. cinerea infection, suggesting that at least part of the responses activated by B. cinerea are mediated, directly or indirectly, by OGs (Ferrari et al. 2007). Therefore, OGs represent a valuable tool to analyse the mechanisms involved in plantpathogen interaction.

In this study, using genetic, biochemical and pharmacological approaches, we provided evidence that OGs induced a NR-dependent NO production together with an increased NR activity and NR transcript accumulation. In addition, NO production was sensitive to the mammalian NOS inhibitor L-NAME. Intriguingly, L-NAME also impaired OG-induced NR activity, thus questioning the mode of action of this widely used compound. Analysis of the signalling pathway involving NO showed that its production was $\mathrm{Ca}^{2+}$ dependent and occurred downstream of the putative plasma membrane cyclic nucleotidegated channel CNGC2. Furthermore, NO production modulated AtRBOHD-mediated ROS production and the transcriptional activation of defence-related genes encoding the anionic peroxidase PER4 and a $\beta$-1,3-glucanase. Finally, by pharmacological and reverse genetic approaches, we provided evidence that $\mathrm{NO}$, as well as its target genes, contributes to the OG-triggered immunity against B. cinerea. Taken together, our data reinforce the concept that $\mathrm{NO}$ is a key mediator of plant defence responses. 


\section{MATERIALS AND METHODS}

\section{Plant material and growth conditions}

The dnd1 (CNGC2) mutant line (Ali et al. 2007) was a gift from Dr Berkowitz (University of Connecticut, USA). The rbohD mutant was kindly provided by Dr Torres (Universidad Politecnica de Madrid,Spain). The double NR nialnia2 mutant (NR1-Ds and NR2 deletion mutant) was kindly provided by S. Neill (University of the West of England-UK). Mutants impaired in anionic peroxidase PER4 (At1g14540) were Per4-1 (N655479/SALK_544730) and Per4-2 (N661 085/SALK_110617), and in $\beta$-1-3-glucanase (At3g55430) was Glu (N642531/SALK_142531). Seeds of these mutant lines and of the wild-type Col-0 were obtained from Nottingham Arabidopsis Stock Center (NASC). All mutant lines used in this work are in the Col-0 background.

The plants were cultivated in commercial soil (Jiffy-7, Puteaux, France) in a climate-controlled growth chamber (KBW, Binder, Germany) with a $10 \mathrm{~h}$ light $\left(175 \mu \mathrm{E} \mathrm{s}^{-1}\right.$ light intensity), $14 \mathrm{~h}$ dark cycle with the following settings: $20^{\circ} \mathrm{C}$ light, $18{ }^{\circ} \mathrm{C}$ dark; $70 \%$ relative humidity light $/ 95 \%$ dark. Plants were fertilized every week with a modified Hoagland nutrient solution containing $1.25 \mathrm{~mm} \quad \mathrm{KNO}_{3}, 1.5 \mathrm{~mm}$ $\mathrm{Ca}\left(\mathrm{NO}_{3}\right)_{2}$. As the nia1nia2 double mutant could not assimilate nitrate and is affected in its development, we restored normal growth by watering the mutants with a medium supplemented with $10 \mathrm{~mm}$ ammonium citrate (Cantrel et al. 2010). Under these conditions, no significant differences of growth were observed between 4-week-old Col-0 wild type and nialnia2 mutants; the average shoot biomasses being $196 \mathrm{mg}$ [standard deviation (SD) = 76] for Col-0 and $230 \mathrm{mg}$ $(\mathrm{SD}=80)$ for nialnia2.

\section{Chemicals}

All chemicals were purchased from Sigma-Aldrich (St Louis, MO, USA) except L-NAME ( $\mathrm{N}^{\mathrm{G}}$-nitro-L-arginineméthyl ester) which was from ALEXIS Biochemicals (San Diego, CA, USA). Sodium tungstate, lanthanum chloride, L-NAME and cPTIO ((4-carboxyphenyl)-4,4,5,5tetramethylimidazoline-1-oxyl-3-oxide) were dissolved in water. DAF-2DA (4,5-diaminofluorescein diacetate) was received as a stock solution of $5 \mathrm{~mm}$ in dimethyl sulfoxide (DMSO). Diphenylene iodonium (DPI) was dissolved in DMSO.

OGs, with an average DP of 25, were obtained from GOEMAR (Saint Malo, France). OGs were dissolved in water at a working concentration of $2.5 \mathrm{mg} \mathrm{mL}^{-1}$.

\section{NO measurements}

NO production was monitored using 4,5-diaminofluorescein diacetate (DAF-2DA; Sigma-Aldrich), a membrane-permeable derivative of the NO-sensitive fluorophore 4,5-diaminofluorescein. This method is indirect and relies on the measurement of reactive nitrogen species (notably $\mathrm{N}_{2} \mathrm{O}_{3}$ and $\mathrm{NO}^{+}$) derived from $\mathrm{NO}$ auto-oxidation that nitrosate DAF-2 to yield the highly fluorescent DAF-2 triazole (DAF-2T; Jourd'heuil 2002).

Detection of DAF2 fluorescence in leaf discs $(8 \mathrm{~mm}$ diameter) was performed according to Cantrel et al. (2011). Briefly, leaf discs excised from plants were infiltrated under vacuum for $3 \mathrm{~min}$ with an aqueous solution of $20 \mu \mathrm{M}$ DAF2DA and $2.5 \mathrm{mg} \mathrm{mL}^{-1}$ of OGs in $50 \mathrm{~mm}$ Tris- $\mathrm{HCl}$ (pH 7.5). For control treatment, OGs were replaced by an equivalent volume of water. L-arginine supplementation of nia1nia2 double mutant (and Col-0 as control) was performed by infiltrating the leaf discs with $1 \mathrm{~mm}$ L-arginine. After infiltration, the discs were washed with Tris- $\mathrm{HCl}$ (50 mM, $\mathrm{pH}$ 7.5). Each disc was put in separate well of 96 well plates (Microtest ${ }^{\mathrm{Tm}}$ flatbottom; Becton Dickinson Europe, Meylan, France) in $200 \mu \mathrm{L}$ Tris- $\mathrm{HCl}$ (50 mm, pH 7.5) with OGs or water. The increase of DAF-2T fluorescence triggered by OGs was measured using a spectrofluorometer (Mithras; Berthold Technologies, Bad WildBad, Germany). Fluorescence was measured with a $485 \mathrm{~nm}$ excitation and a $535 \mathrm{~nm}$ emission filters for $12 \mathrm{~h}$. Eight leaf discs were used for each treatment. Fluorescence was expressed as relative fluorescence units (arbitrary units: au).

Importantly, because the leaf discs have been vacuum infiltrated and kept in buffer solution for up to $12 \mathrm{~h}$ in the dark, we could not exclude the possibility that they became hypoxic during the experiment. Because constant oxygen availability is important for ROS formation and NO autooxidation resulting in the formation of DAF-reactive forms, hypoxia might alter the rate of $\mathrm{H}_{2} \mathrm{O}_{2}$ and DAF-2T synthesis. To reduce this risk, the plates were shaken during the experiment. Furthermore, we found that when leaf discs were vacuum infiltrated $24 \mathrm{~h}$ before adding OGs in the solution in which leaf discs were fluttering, the production of $\mathrm{H}_{2} \mathrm{O}_{2}$ and increase of DAF-2T fluorescence were still occurring, minimizing the influence of hypoxia in the measurement (data not shown).

\section{Gene expression analysis by quantitative real-time qPCR}

Treated leaves were immediately frozen in liqud nitrogen. Total RNA was isolated with Tri reagent (Molecular Research Centre Inc., Cincinnati, OH, USA). Nucleic acid concentration was estimated at $260 \mathrm{~nm}$. Purity of total RNA was assessed by determining the 260/280 ratio and the integrity was checked by agarose gel electrophoresis.

First-strand cDNA templates were produced by using the cDNA synthesis kit (Superscript ${ }^{\mathrm{Tm}}$ III Reverse Transcriptase; Invitrogen, Carlsbad, CA, USA) from $2 \mu \mathrm{g}$ of total RNA treated with DNaseI (Sigma-Aldrich) as recommended by the manufacturer. Reactions were performed in a final volume of $20 \mu \mathrm{L}$ containing $8 \mu \mathrm{L}$ of cDNA (dilution 1/80) sample, $200 \mathrm{~nm}$ of forward and reverse primers, and $10 \mu \mathrm{L}$ of real-time SYBR Green mix (Abgene; Thermo Scientific, Surrey, UK). qPCR was conducted with a Mastercycler (Sequence Detection System; Applied Biosystem, Foster City, CA, USA) in 96 well plates (Optical Reaction Plate with Barcode; Applied Biosystem). Gene-specific 
primers were as follows: PER4-At1g14540 (5'-cactggttcaga tggacaaa- $3^{\prime}$ and $5^{\prime}$-aacaaacgaattatcgctgc- $\left.3^{\prime}\right), P L P 2-A t 2 g 265$ 60 (5'-aagaaaagaagatccgagac- $3^{\prime}$ and $5^{\prime}$-attcaaacgtacaagtga cc-3'), CHI-IV-At3g54420 (5'-tgttgactcccaccattt-3' and 5'cggtcgatccaactctac- $\left.3^{\prime}\right)$ and $\beta$-1,3-glucanase-At3g55430 (5'cttcgctggaactggtatct- $3^{\prime}$ and $5^{\prime}$-gcagaatctcatttccgact- $\left.3^{\prime}\right)$. The specificity of the primers was tested by sequencing the PCR products. PCR amplification efficiency of target DNA was examined to measure linearity of dilution. For each gene, a standard curve was generated with serial dilutions of plasmids containing the respective PCR product. These standard curves showed similar slopes demonstrating an efficiency of more than $90 \%$.

Expression levels were calculated relative to the housekeeping gene (HK) UBQ10- At4g05320 (5'-ctatatgctc gctgctgagc- $3^{\prime}$ and $5^{\prime}$-aagccaggcagagacaactc- $3^{\prime}$ ) using the comparative threshold cycle method, where $\mathrm{Ct}$ represents the threshold cycle for target amplification: $\Delta \Delta \mathrm{Ct}=$ $\Delta \mathrm{Ct}_{\text {gene of interest }}-\Delta \mathrm{Ct}_{\mathrm{HK}}$. The $2^{-\Delta \Delta \mathrm{CT}}$ method was used to analyse the relative changes in gene expression from realtime quantitative PCR experiments (Livak \& Schmittgen 2001).

\section{In vivo NR activity}

In vivo NR activity was assayed by the protocol of $\mathrm{Yu}$, Sukumaran \& Marton (1998) with minor modifications. NR activity was measured in a spectrophotometric assay by determining the amount of $\mathrm{NO}_{2}^{-}$released from the tissue. Leaf discs were weighed, vacuum infiltrated with or without OGs in Tris- $\mathrm{HCl}$ for $3 \mathrm{~min}$ and incubated for $4 \mathrm{~h}$ within the respected solutions. After incubation, leaf discs were transferred into $1 \mathrm{~mL}$ of reaction buffer [ $40 \mathrm{~mm} \mathrm{KNO}_{3}$, $0.08 \mathrm{mM} \mathrm{Na}_{2} \mathrm{HPO}_{4}, 0.02 \mathrm{~mm} \mathrm{NaH} \mathrm{PO}_{4}$ and $4 \%$ (v/v) $n$ propanol, $\mathrm{pH}$ 7.5] and incubated in the dark for $2 \mathrm{~h}$. The reaction was stopped by the addition of $200 \mu \mathrm{L}$ of $1 \%$ sulphanilamide (dissolved in $3 \mathrm{~N} \mathrm{HCl}$ ) and $200 \mu \mathrm{L}$ of $0.05 \% N$-(1-napthyl)ethylenediamine hydrochloride. The concentration of $\mathrm{NO}_{2}^{-}$was determined by measuring the optical density (OD) of the solution at $540 \mathrm{~nm}$.

\section{$\mathrm{H}_{2} \mathrm{O}_{2}$ measurements}

$\mathrm{H}_{2} \mathrm{O}_{2}$ was measured using a luminol-dependent assay (Keppler, Baker \& Atkinson 1989). Two millimetre leaf discs of 4-week-old Arabidopsis plants were excised and five discs per condition were incubated in $200 \mu \mathrm{L}$ of $\mathrm{H}_{2} \mathrm{O}$ overnight in assay tubes. Then, $4 \mu \mathrm{L}$ of $3 \mathrm{~mm}$ luminol solution (final concentration $60 \mu \mathrm{M}$ ) was added to the tubes 5 min before treatment. Luminescence was measured in a luminometer (Lumat LB 9507; Berthold Technologies) for a total time of $50 \mathrm{~min}$. Measurements were integrated over $10 \mathrm{~s}$ periods.

\section{B. cinerea culture and infection method}

B. cinerea strain BMM (Zimmerli et al.2001) was grown on Petri plates containing potato dextrose agar (PDA; DIFCO,
Lawrence, KS, USA) for $10-12 \mathrm{~d}$ (light $10 \mathrm{~h}, 20{ }^{\circ} \mathrm{C}$; dark $\left.14 \mathrm{~h}, 18^{\circ} \mathrm{C}\right)$. Spores were harvested in water and subsequent filtration through glass wool to remove hyphae. Spores were quantified under a microscope. About $1 \mathrm{~h}$ before infection, spores were diluted in one-fourth potato dextrose broth (PDB; DIFCO) to obtain a final concentration of $5 \times 10^{4}$ spores $\mathrm{mL}^{-1}$. For assessment of symptom in plants, droplets of $6 \mu \mathrm{L}$ of spore suspension $\left(5 \times 10^{4}\right.$ spores $\mathrm{mL}^{-1}$ ) were deposited on six leaves of 4-week-old plants (wild type and mutants). Plant infections were performed in covered plastic box to maintain high humidity and returned to the growth chamber. Lesion diameters were measured after $72 \mathrm{~h}$ of inoculation using callipers. Results were analysed by one-way analysis of variance (ANOvA) on ranks, followed by Dunnett's test $(P>0.05)$, using the SigmaPlot software (Jandel Scientific, Chicago, IL, USA).

\section{RESULTS}

\section{OGs induce NO production in A. thaliana (Col-0) leaf discs}

The ability of OGs to induce NO production in Col-0 was investigated by monitoring the time course of DAF-2T fluorescence accumulation in OG-treated leaf discs preinfiltrated with DAF-2DA (Fig. 1). A similar method was recently used to measure NO production in response to cold stress (Cantrel et al. 2011). DAF-2T is a fluorescent compound resulting from the nitrosation of DAF-2 by reactive nitrogen species derived from $\mathrm{NO}$ auto-oxidation such as dinitrogen trioxide $\mathrm{N}_{2} \mathrm{O}_{3}$ (Besson-Bard et al. 2008b). OGs triggered an increase in fluorescence which occurred within 30 min (Fig. 1, Supporting Information Figs S2 \& S3). Increase of fluorescence remained constant thereafter and reached almost $190 \%$ of the control value at $6 \mathrm{~h}$ (Fig. 1B). A slight increase in DAF fluorescence was also observed in control leaf discs (Fig. 1A). This background production might be related to constitutive NO production and/or to the wounding triggered during leaf disc preparation. To argue that the OG-induced rise of fluorescence was related to NO production, a similar experiment was performed in the presence of cPTIO. This compound is a stable organic radical that oxidizes the $\mathrm{NO}$ molecule to form the ${ }^{\circ} \mathrm{NO}_{2}$ radical (Akaike \& Maeda 1996). The ability of cPTIO to scavenge NO exogenously applied or endogenously produced in biological samples has been reported in many studies (see, for instance, Bright et al. 2006; Planchet and Kaiser, 2006; Zottini et al. 2007; Besson-Bard et al. 2008b). As shown in Fig. 1, fluorescence increase in both OG-treated and control leaf discs was markedly suppressed by cPTIO.

The DAF-2-based assay for NO detection has been shown to be a suitable technique for the detection of NO (Vandelle \& Delledonne 2008). However, as specified above, this method is indirect as it allows the measurement of NO-derived species (Besson-Bard et al. 2008b). Furthermore, doubts have arisen over the specificity of DAF-2 for NO-related species (for review, see Mur et al. 2011). Therefore, to strengthen our assumption that OGs trigger NO 
(a)

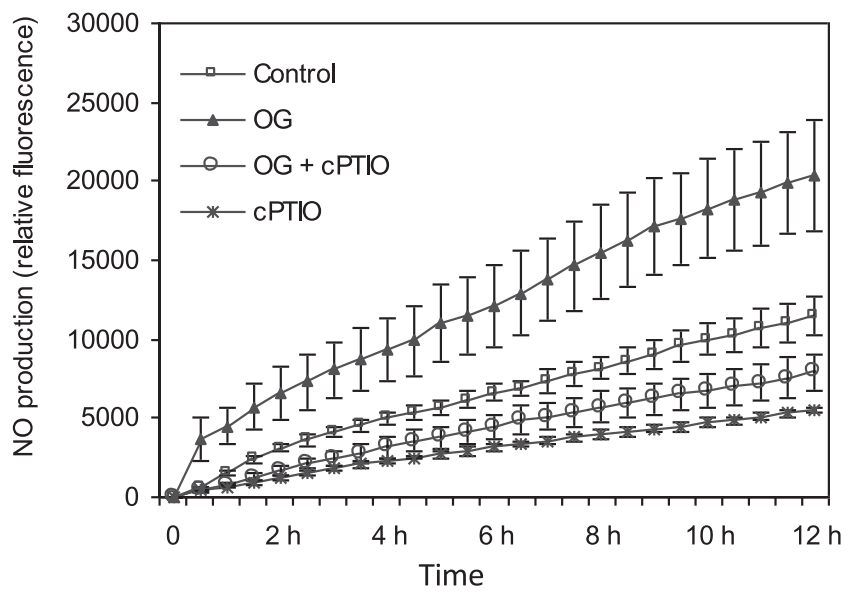

(b)

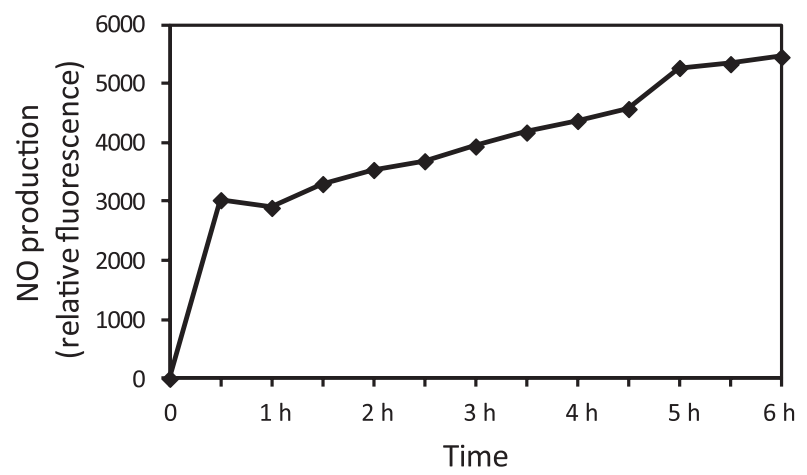

Figure 1. (a) Time course of nitric oxide (NO) production in oligogalacturonide (OG)-treated Col-0 leaf discs. NO production was monitored using diaminofluorescein diacetate (DAF-2DA) $(20 \mu \mathrm{M})$ in the absence (control) or presence of OGs $\left(2.5 \mathrm{mg} \mathrm{mL}^{-1}\right)$, with or without NO scavenger (cPTIO $500 \mu \mathrm{M}$ ). Each value represents the mean of 8 measurements \pm standard deviation. This experiment is representative of 10 independent experiments using independent biological material. (b) Time course of OG-induced NO production between 1 and $6 \mathrm{~h}$. Fluorescence values of control (water treatment) were subtracted from values obtained in response to OGs.

synthesis, we used a second approach for NO measurement based on the use of the CuFL fluorescent probe. The CuFL probe reacts directly and rapidly with $\mathrm{NO}$ and is believed to be more sensitive than DAF-2A (Supporting Information Fig. S1; Lim, Xu \& Lippard 2006). However, NO detection with $\mathrm{CuFL}$ is less convenient than DAF-2DA as freshly prepared probe is poorly stable and could not be used after $1 \mathrm{~h}$ (manufacturer's instructions). Compared with control, OGs triggered a significant increase of CuFL fluorescence (Supporting Information Fig. S2). As expected, this fluorescence increase was completely suppressed by cPTIO, thus further supporting our hypothesis that OGs trigger NO synthesis.

\section{OG-induced NO production is L-NAME sensitive}

Several studies have suggested that the production of NO from L-arginine in plants could involve an unidentified NOS-like enzyme in which activity is sensitive to mammalian NOS inhibitors (Corpas et al. 2006, 2011; Cueto et al. 1996; Modolo et al. 2002; del Río et al. 2004). To investigate the putative involvement of a NOS-like enzyme, we checked the sensitivity of OG-induced NO production to L-NAME, a widely used mammalian NOS competitive inhibitor. L-NAME was reported to suppress NO synthesis, as well as NOS-like activities, in plant tissues and cell suspensions exposed to various stimuli. L-NAME reduced OG-induced NO production in Col-0 leaf discs by $40 \%$ after $12 \mathrm{~h}$ of treatment (Fig. 2). This inhibition was observed at earlier time point (Supporting Information Fig. S3a).

\section{NR is involved in OG-induced NO production}

The potential involvement of NR as a NO source was investigated using a combination of genetic and pharmacological approaches. This analysis was completed by following the incidence of OGs on NR activities and transcript accumulation.

We first investigated the putative contribution of NR as an enzymatic source for NO production during OG treatment using the NR nialnia2 double mutant (Fig. 3a and Supporting Information Fig. S3b). OG-induced increase of DAF-2T fluorescence was partially reduced by about $50 \%$ in nialnia2 as compared with wild-type Col-0 leaf discs. The NO scavenger cPTIO completely suppressed the increase of fluorescence triggered by the elicitor in nialnia2, indicating that the remaining fluorescence measured in the mutant was also due to OG-induced NO production. Interestingly,

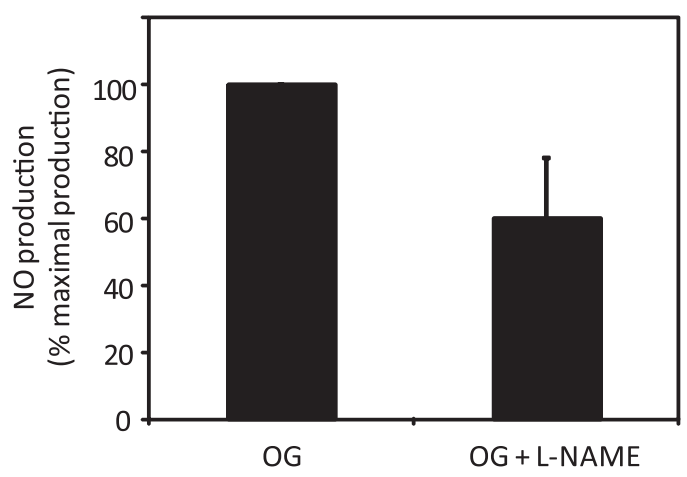

Figure 2. Effect of L-NAME on oligogalacturonide (OG)-induced nitric oxide (NO) production in Col-0 leaf discs. Arabidopsis leaf discs from wild-type (Col-0) plants loaded with diaminofluorescein diacetate (DAF-2DA) $(20 \mu \mathrm{M})$ were treated by OGs $\left(2.5 \mathrm{mg} \mathrm{mL}^{-1}\right)$ with or without a pretreatment with L-NAME (5 mM). NO accumulation was determined after $12 \mathrm{~h}$ of treatment and expressed as a percentage of the maximal response after subtracting background fluorescence of corresponding control. Each value is a mean \pm standard deviation of three independent experiments. 
(a)

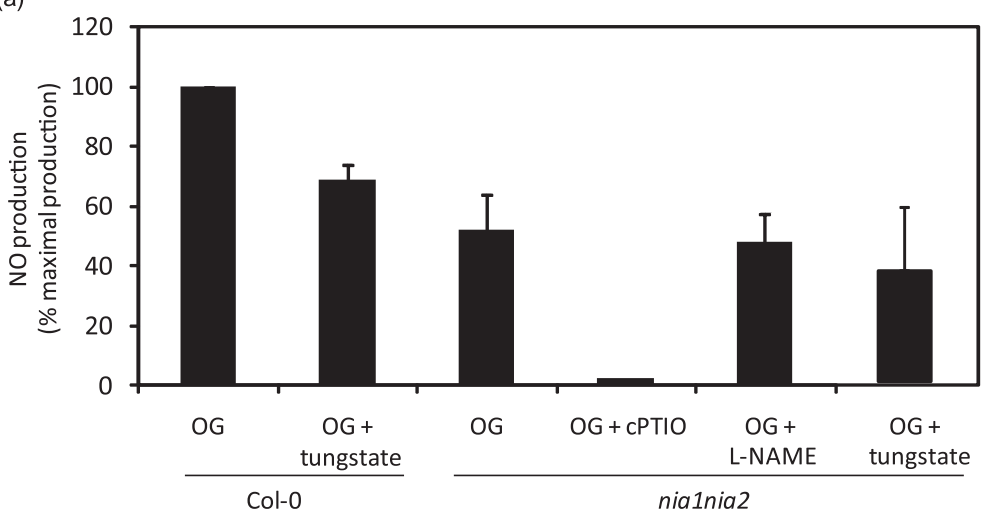

(b)

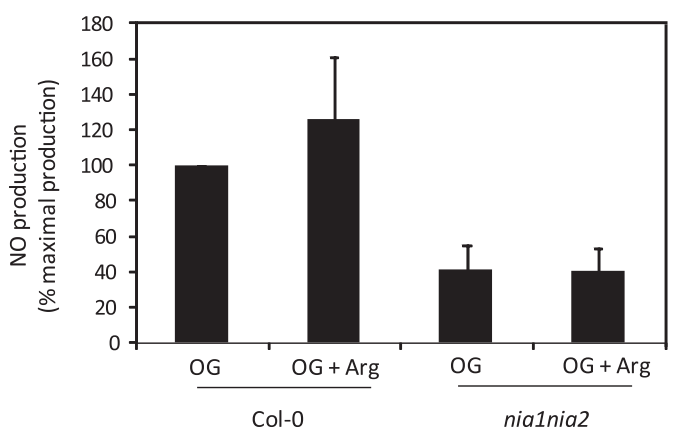

(c)

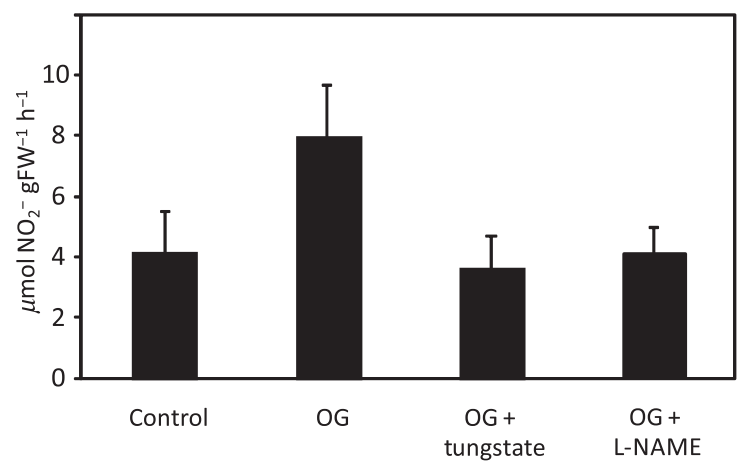

(d)

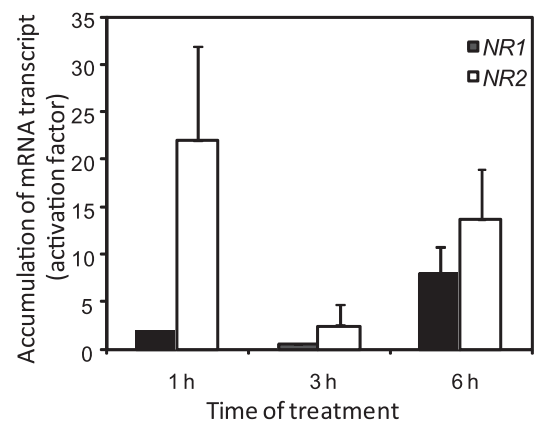

Figure 3. Involvement of nitrate reductase (NR) in oligogalacturonide (OG)-induced nitric oxide (NO) production. (a) Diaminofluorescein diacetate (DAF-2DA)-infiltrated (20 $\mu \mathrm{M})$ Arabidopsis leaf discs from wild type (Col-0), and nialnia2 plants were treated by OGs $\left(2.5 \mathrm{mg} \mathrm{mL}^{-1}\right)$ or water. The effect of tungstate $(0.1 \mathrm{~mm})$ and/or L-NAME $(5 \mathrm{~mm})$ on OG-induced NO production was analysed on Col-0 and nialnia2 leaf discs. Bar graph is the mean of five independent experiments using independent biological material (eight replicates per experiment). NO accumulation determined after $12 \mathrm{~h}$ of treatment is expressed as a percentage of the maximal response measured in wild-type Col-0 leaf discs treated with OGs, after subtracting background fluorescence of corresponding control. (b) Effect of L-arginine on OG-induced NO production in Col-0 and nialnia2 leaf discs. Arabidopsis leaf discs loaded with DAF-2DA $(20 \mu \mathrm{M})$ were treated by OGs $\left(2.5 \mathrm{mg} \mathrm{mL}^{-1}\right)$ with or without L-arginine $(1 \mathrm{mM})$. NO accumulation was determined after $12 \mathrm{~h}$ of treatment and expressed as a percentage of the maximal response after subtracting background fluorescence of corresponding control. Each value is a mean \pm standard deviation (SD) of three independent experiments. (c) In vitro NR activity in wild-type (Col-0) leaf discs treated with water, OGs, OGs + tungstate $(0.1 \mathrm{~mm})$ and OGs + L-NAME. Each value represents the mean \pm SD of three independent experiments performed using independent biological materials. Tungstate and L-NAME alone did not modify significantly NR activity measured in control. (d) Time course of accumulation of NR1 and NR2 mRNA transcripts in Col-0 leaf discs treated with OGs or water. Transcribed mRNAs were analysed by real-time quantitative RT-PCR. Levels of transcripts were calculated using $2^{-\Delta \Delta C T}$ method. This experiment is representative of three independent experiments using independent biological material. Bars indicate average expression ( \pm SD) of three replicates.

L-NAME did not reduce the remaining NO production observed in the NR mutant (Fig. 3a). To further confirm the involvement of NR as a NO source, we also examined the effect of the NR inhibitor tungstate on NO production. Pretreatment of Col-0 leaf discs with tungstate reduced OG-triggered NO production by almost 30\% (Fig. 3a and Supporting Information Fig. S3b). In contrast, pretreatment of nia1nia2 with tungstate did not modify significantly the reduced NO production observed in the double mutant in response to OGs alone, suggesting that the remaining NO production in nialnia2 is probably not due to residual NR activity (Fig. 3a).

Modolo et al. (2006) demonstrated that the nialnia2 double mutant has much lower L-arginine content in leaves (almost 10 times lower) as compared with wild-type plants, suggesting that the L-arginine-dependent pathway for NO synthesis could be down-regulated in the nialnia2 mutant. To check this possibility, leaf discs were co-infiltrated with OGs and L-arginine. We observed that L-arginine supply did not restore NO production in the nialnia2 mutant (Fig. 3b), strongly suggesting that the reduced NO production in the nialnia2 mutant was first related to the impaired expression of the corresponding genes.

To complete this analysis, we next investigated whether the involvement of NR as a NO enzymatic source in response to OGs was correlated with changes in NR activity and transcript accumulation. Firstly, we quantified in vivo NR activity in A. thaliana Col-0 leaf discs. As shown in Fig. 3b, OG treatment induced a twofold increase of NR activity as compared with control after $4 \mathrm{~h}$ of treatment. As 
expected, OG-induced NR activity was completely suppressed by tungstate (Fig. 3b). In the nialnia2 mutant, a residual activity representing $2-3.3 \%$ of the activity measured in Col-0 was detected (Supporting Information Fig. S7). In order to better understand the link between Arg- and NR-dependent pathways for NO production, we monitored NR activity in the presence of L-NAME (Fig. 3b). Surprisingly, L-NAME inhibited OG-induced NR activity to a similar extent than tungstate. Secondly, we estimated $N R 1$ and NR2 mRNA transcript accumulation by quantitative real-time RT-PCR. A rise in the accumulation of both transcripts occurred in response to OG (Fig. 3c). However, NR2 $m$ RNA showed noticeable higher and faster accumulation than NR1 mRNA (Fig. 3c). Furthermore, $N R 2$ transcripts showed a biphasic accumulation, the lowest accumulation being observed at $3 \mathrm{~h}$ post-treatment. Taken together, these results indicate that OGs elicit a NR-dependent NO production together with an increase of NR activity and transcript accumulation.

\section{$\mathrm{Ca}^{2+}$ influx modulates NO production in response to OGs}

The $\mathrm{Ca}^{2+}$ dependency of NO production has been previously shown in several studies (Courtois et al. 2008). In particular, Ali et al. (2007) identified CNGC2, a plasma membrane cyclic nucleotide-gated channel (CNGC) member, as a key $\mathrm{Ca}^{2+}$-permeable channel linking lipopolysaccharide (LPS)-triggered $\mathrm{Ca}^{2+}$ influx to downstream NO production in A. thaliana. Furthermore, OGs have been shown to trigger a fast and transient elevation in cytosolic-free $\mathrm{Ca}^{2+}$ in A. thaliana, this process being suppressed by the calcium channel blocker lanthanum $\left(\mathrm{La}^{3+}\right.$; Moscatiello et al. 2006). Based on these data, we tested whether CNGC2 could act upstream of OG-evoked NO generation using the dnd1 (defence no death1) mutant impaired in functional $\mathrm{CNGC2}$. In control leaf discs, Col-0 and $d n d 1$ mutant showed approximately similar level of basal DAF-2T fluorescence (data not shown). In response to OGs, dnd1 leaf discs displayed a lower increase of DAF-2T fluorescence as compared with Col-0. Indeed, NO production in $d n d 1$ leaf discs reached $49 \%$ of the value measured in Col-0 leaf discs (Fig. 4). Accordingly, a significant decrease in OG-induced NO production occurred also in Col-0 leaf discs pretreated with $\mathrm{La}^{3+}$ (Fig. 4).Therefore, the reduced NO production in both dnd 1 and $\mathrm{La}^{3+}$-treated Col-0 plants suggests a role for $\mathrm{Ca}^{2+}$ influx in mediating the OG signal to NO production.

\section{NO modulates OG-triggered ROS production in A. thaliana leaf discs}

Oxidative burst is a common early response of plant cells to pathogen attack and elicitor treatment. Galletti et al. (2008) demonstrated that $\mathrm{OG}$ treatment induced an oxidative burst mediated by the NADPH oxidase AtRBOHD. In order to analyse a potential functional link between ROS

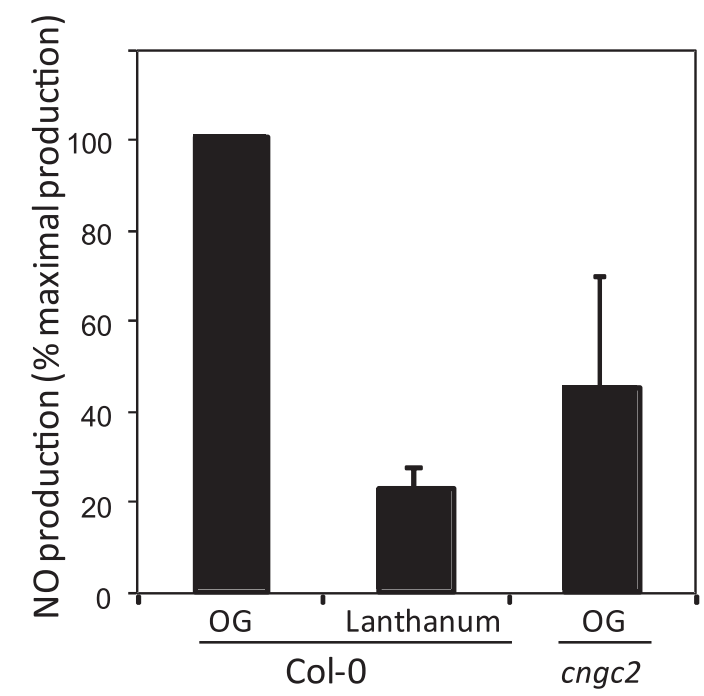

Figure 4. Involvement of $\mathrm{Ca}^{2+}$ influx in oligogalacturonide (OG)-induced nitric oxide (NO) production. OG-induced NO production was measured in Col-0 or $c n g c 2$ leaf discs loaded with diaminofluorescein diacetate (DAF-2DA) $(20 \mu \mathrm{m})$. Leaf discs were treated by OGs $\left(2.5 \mathrm{mg} \mathrm{mL}^{-1}\right)$ in the presence or absence of lanthanum $(5 \mathrm{~mm})$. Histogram represents the NO production measured after $12 \mathrm{~h}$ of treatment and expressed as a percentage of the maximal response after subtracting background fluorescence of corresponding control. Each value is a mean \pm standard deviation of three independent experiments.

and NO production in response to OGs, the role of NO in controlling the oxidative burst was first studied. ROS production was measured in leaf discs using a luminol-based assay. In response to OGs, ROS burst was detectable approximately $3 \mathrm{~min}$ after elicitation, reached a maximum after $10 \mathrm{~min}$ and declined thereafter (Fig. 5a). These data fit well with our recent report showing that $\mathrm{OG}$ induces a fast and transient ROS production in A. thaliana cell suspensions (Dubreuil-Maurizi et al. 2011). It also indicates that both ROS and NO production occur simultaneously (Fig. 1, Supporting Information Figs S2 \& S3). As expected, the ROS production was sensitive to the NADPH oxidase inhibitors DPI (Fig. 5a) and also quinacrine, a general inhibitor of oxidases (not shown). Furthermore, it was completely abolished in the RbohD mutant as reported by Galletti et al. (2008; Fig. 5b). Pretreatment of leaf discs with cPTIO, L-NAME or $\mathrm{La}^{3+} 10$ min prior to OG treatment led to an inhibition of OG-stimulated ROS elevation (Fig. 5b). Surprisingly, the nialnia 2 NR mutant, which displayed a reduced NO synthesis (Fig. 2), exhibited a similar increase of ROS production in response to OGs as compared with Col-0 (Fig. 5b).

To complete this analysis, we also verified NO level in response to OGs in AtRbohD. NO production in rbohD mutant was only $20 \%$ lower than Col-0 at 12 h (Fig. 5c). Compared with Col-0, and taking into account variability, we considered this difference poorly significant, indicating that ROS produced by AtRBOHD do not, or slightly, control OG-induced NO production. 
(a)

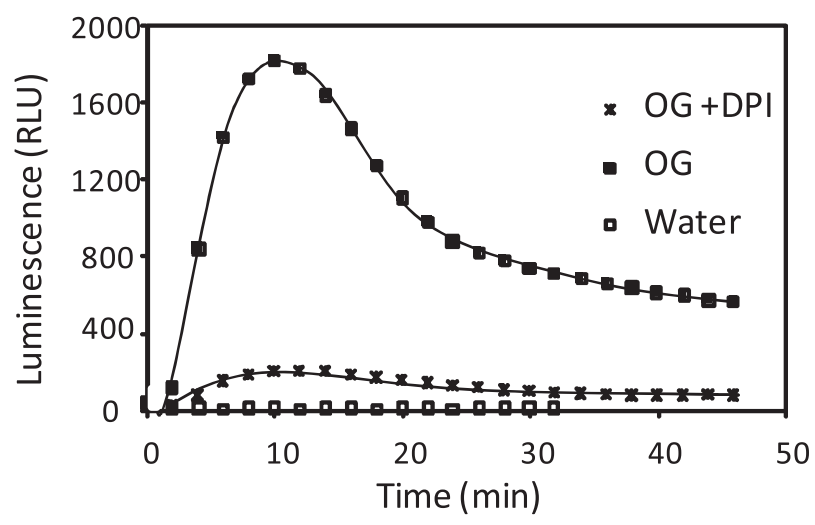

(c)

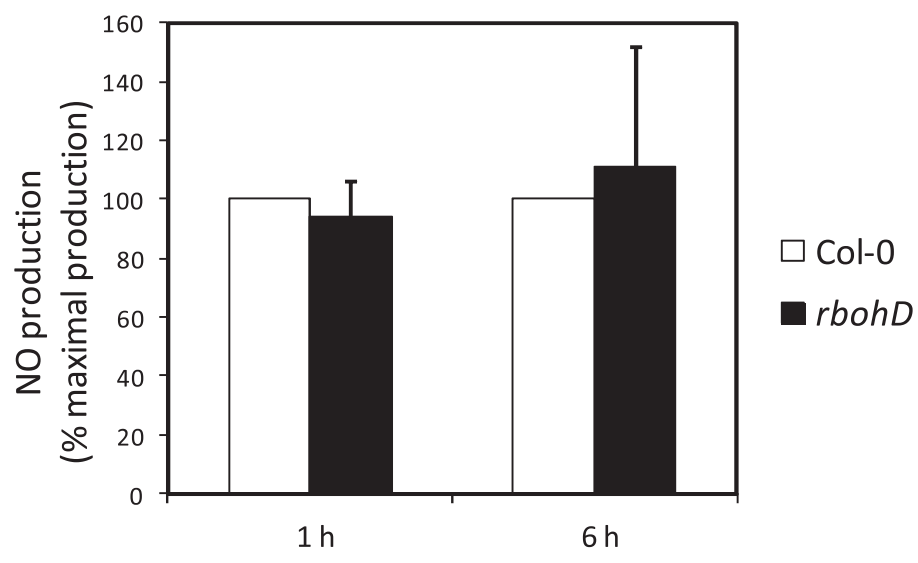

(b)

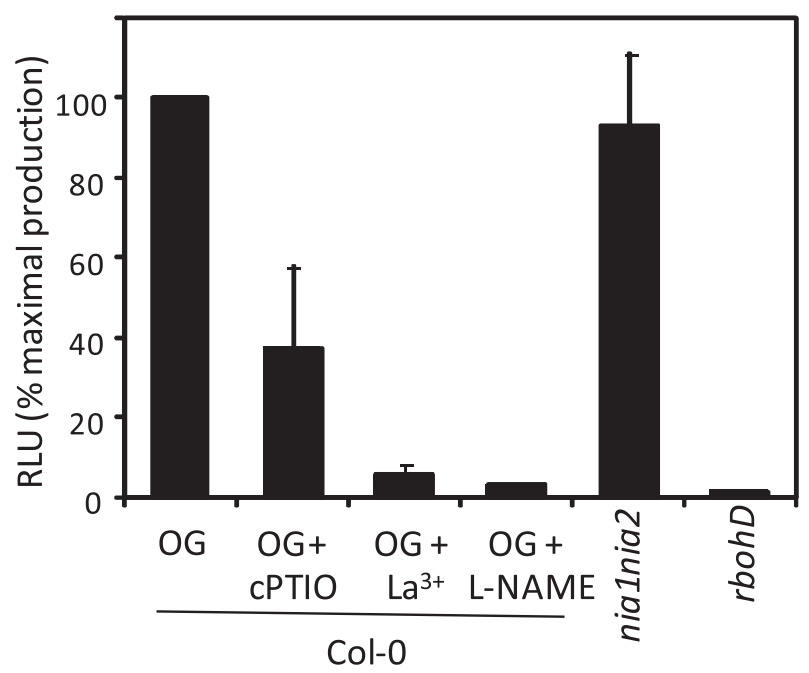

Figure 5. Relationships between reactive oxygen species (ROS) and nitric oxide (NO) production in plants elicited by oligogalacturonides (OGs). (a) Accumulation of extracellular $\mathrm{H}_{2} \mathrm{O}_{2}$ in response to OGs. The production of ROS was measured with a luminol-based assay. Leaf discs from Col-0 plants were treated with water (control) or OGs $\left(2.5 \mathrm{mg} \mathrm{mL}^{-1}\right)$. Diphenylene iodonium (DPI) $(10 \mu \mathrm{M})$ was added $10 \mathrm{~min}$ before treatment. Treatment with DPI alone did not induce luminescence. The data are representative of three experiments. (b) Effect of $\mathrm{NO}$ on $\mathrm{H}_{2} \mathrm{O}_{2}$ production in response to OGs. $\mathrm{H}_{2} \mathrm{O}_{2}$ production was measured as described in (a) and was represented as a percentage of the maximum ROS production observed in leaf discs of Col-0 and mutants elicited by OGs after subtracting background fluorescence of corresponding control. Luminescence values were recorded at 10 min of treatment (peak maximum). cPTIO $(500 \mu \mathrm{M})$, L-NAME $(5 \mathrm{~mm})$ and lanthanum $\left(\mathrm{La}^{3+} ; 5 \mathrm{~mm}\right)$ were added 10 min before treatment. (c) OG-induced NO production in Col-0 and $r b o h D$ leaf discs. NO accumulation was determined after 1 and $6 \mathrm{~h}$ of treatment and expressed as a percentage of the maximal response after subtracting background fluorescence of corresponding control. Values are a mean \pm standard deviation of three independent experiments. RLU, relative luminescence units.

\section{NO regulation of OG-responsive genes}

To demonstrate the involvement of NO in the plant defence responses induced by OGs, we monitored the expression of a set of four genes, selected according to previous studies, in leaf discs co-treated with cPTIO or L-NAME. The four genes correspond to At1G14540 encoding an anionic peroxidase (PER4), At2G26560 encoding a phospholipase A2 (PLP2), At3G54420 encoding a chitinase IV (CHI-IV) and At3G55430 encoding a $\beta$-1,3-glucanase. These four genes showed global transcriptional changes when $A$. thaliana plants were treated by OGs (Ferrari et al. 2007) and were found to be up-regulated upon $B$. cinerea infection, a fungal pathogen known to release OGs from plant cell walls (La Camera et al. 2005; Doxey et al. 2007; Ferrari et al. 2007). Furthermore, CHI-IV and $\beta$-1,3-glucanase were identified as putative NO-responsive genes after analysis of publicly available expression data literature (Besson-Bard et al. 2009).

Compared with the control, a clear increase in PER4 and $P L P 2$ transcript levels was observed at $1 \mathrm{~h}$ and, to a lower extent, $3 \mathrm{~h}$ after OG treatment (Fig. 6a). The increase of $\beta$-1,3-glucanase transcript level occurred after $3 \mathrm{~h}$ and decreased, while remaining significant, after $6 \mathrm{~h}$ of treatment (Fig. 6a). In contrast, the expression of $C H I-I V$ gene was not clearly up-regulated in our experiment (data not shown). 
(a)
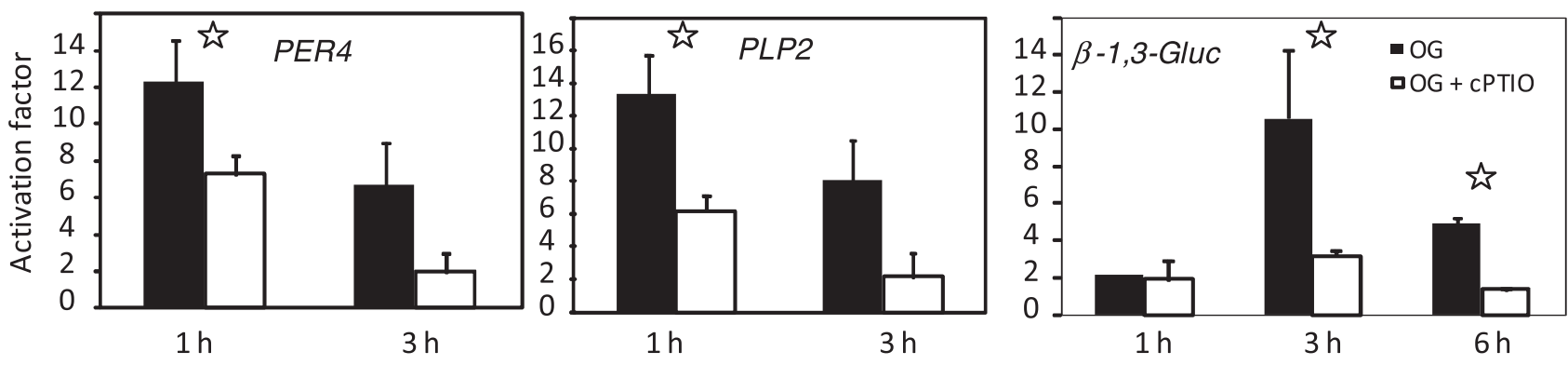

(b)

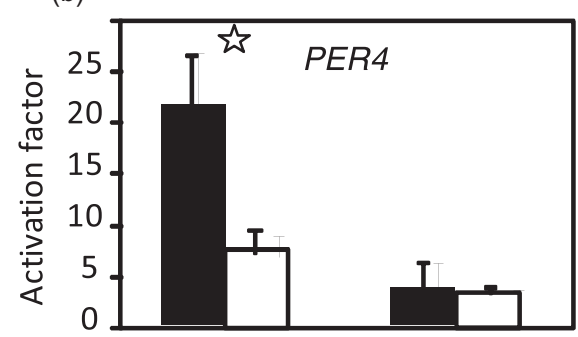

$1 \mathrm{~h}$

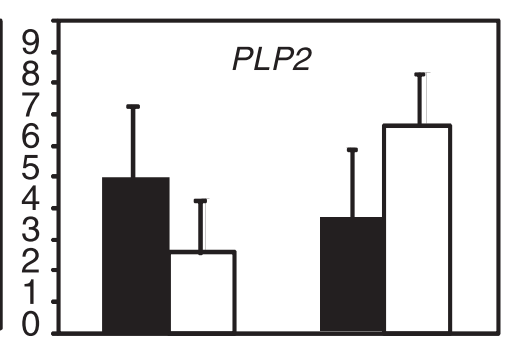

$1 \mathrm{~h}$

$3 \mathrm{~h}$

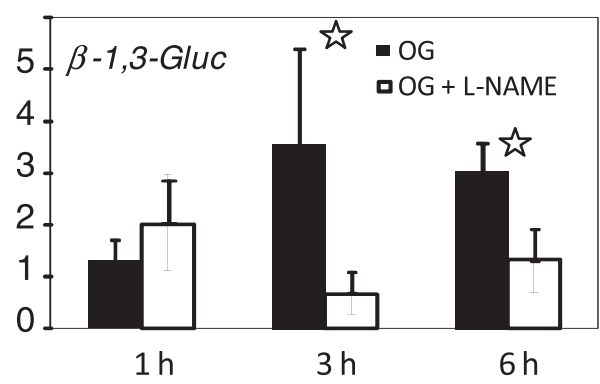

Figure 6. Role of nitric oxide (NO) on transcript accumulation of oligogalacturonide (OG)-responsive genes. (a) Effect of cPTIO treatment on transcript accumulation of OG-responsive genes. Col-0 leaf discs were infiltrated with water or OGs $(2.5 \mathrm{mg} \mathrm{mL}-1)$ in the presence or absence of cPTIO $(500 \mu \mathrm{M})$ and harvested for analysis after different time intervals. This experiment is representative of three independent biological experiments. Bars indicate average expression [ \pm standard deviation (SD)] of three replicates. (b) Effect of L-NAME on transcript accumulation of OG-responsive genes. Col-0 leaf discs were infiltrated with water or with $\mathrm{OGs}\left(2.5 \mathrm{mg} \mathrm{mL}^{-1}\right)$ in the presence or absence of L-NAME $(5 \mathrm{~mm})$ and were harvested for analysis after different time intervals. This experiment is representative of three independent biological experiments. Bars indicate average expression $( \pm \mathrm{SD})$ of three replicates. Statistically significant comparisons are indicated by a star (Student's $t$-test, $P<0.05$ ).

cPTIO reduced the OG-induced up-regulation of these genes (Fig. 6a). However, only PER4 and $\beta$-1,3-glucanase transcript accumulation was affected by L-NAME treatment (Fig. 6b). Interestingly, the level of PLP2 transcript was not significantly different in nialnia2 compared with Col-0 (Supporting Information Fig. S4). This result indicates that PLP2 expression, although cPTIO sensitive, is neither regulated by NR-dependent pathway nor by Argdependent pathway.

\section{NO participates to basal resistance to the fungal pathogen $B$. cinerea}

We used the $A$. thaliana/B. cinerea interaction model to determine the role of $\mathrm{NO}$ and NO/OG-responsive genes in plant defence. B. cinerea is a necrotizing fungus causing several pre- and post-harvest diseases in more than 200 plant species. It was previously demonstrated that OGs are released and accumulate during $B$. cinerea infection. OG release results from $P G$ activity, this activity being required for pathogen virulence (Ten Have et al.1998; Hahn, Darvill \& Albersheim 2001). Arabidopsis leaves were infiltrated with water or different concentrations of cPTIO prior to inoculation with B. cinerea. The average diameter of necrotic lesions of plants pretreated with $500 \mu \mathrm{M}$ cPTIO was significantly larger than in control plants (Fig. 7a). To rule out the possibility that the difference in disease lesions was due to an effect of cPTIO on fungal growth, we assessed the effect of cPTIO on the growth of B. cinerea in vitro. cPTIO has no effect on growth at the concentrations used in susceptibility analysis (Supporting Information Fig. S5).

Finally, we investigated A. thaliana basal resistance to $B$. cinerea in the different genetic background of interest by estimating macroscopic symptoms (e.g. diameter of lesions inflicted by the fungus). We used the double NR mutant nialnia2 affected in OG-induced NO production and T-DNA insertion mutants impaired in the expression of the OGs/NO-inducible genes PER4 and $\beta$-1,3-glucanase genes (per4-1, per4-2 and glu, respectively). Mutants were challenged with $B$. cinerea and disease symptoms were assessed $3 \mathrm{~d}$ post-inoculation. Our results indicate that per4-1, per4-2 and $g l u$ were more susceptible than Col-0, indicating that these two proteins are involved in basal plant resistance to B. cinerea (Fig. 7b). Nialnia2 double mutant was also more susceptible to B. cinerea (Fig. 7b).

\section{DISCUSSION}

\section{OG-induced NO production}

Although many studies highlight a role for NO in plant physiological processes, its detection and quantification is still a major challenge. Several methods for investigating 
(a)
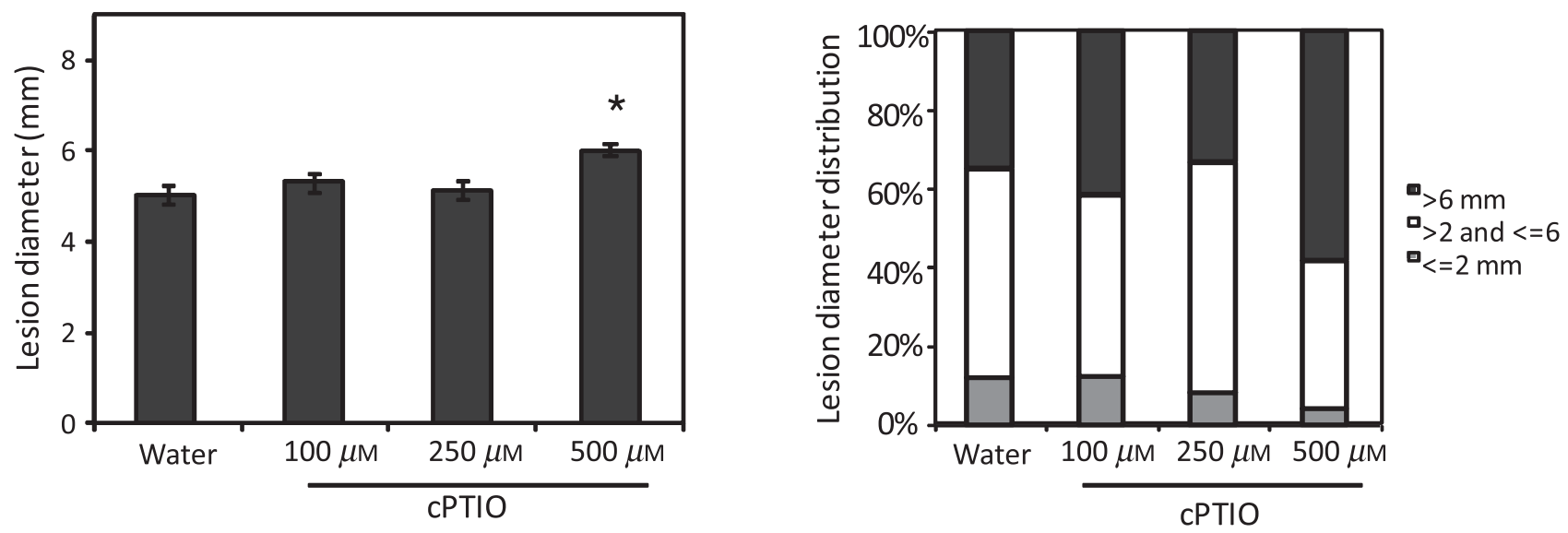

(b)
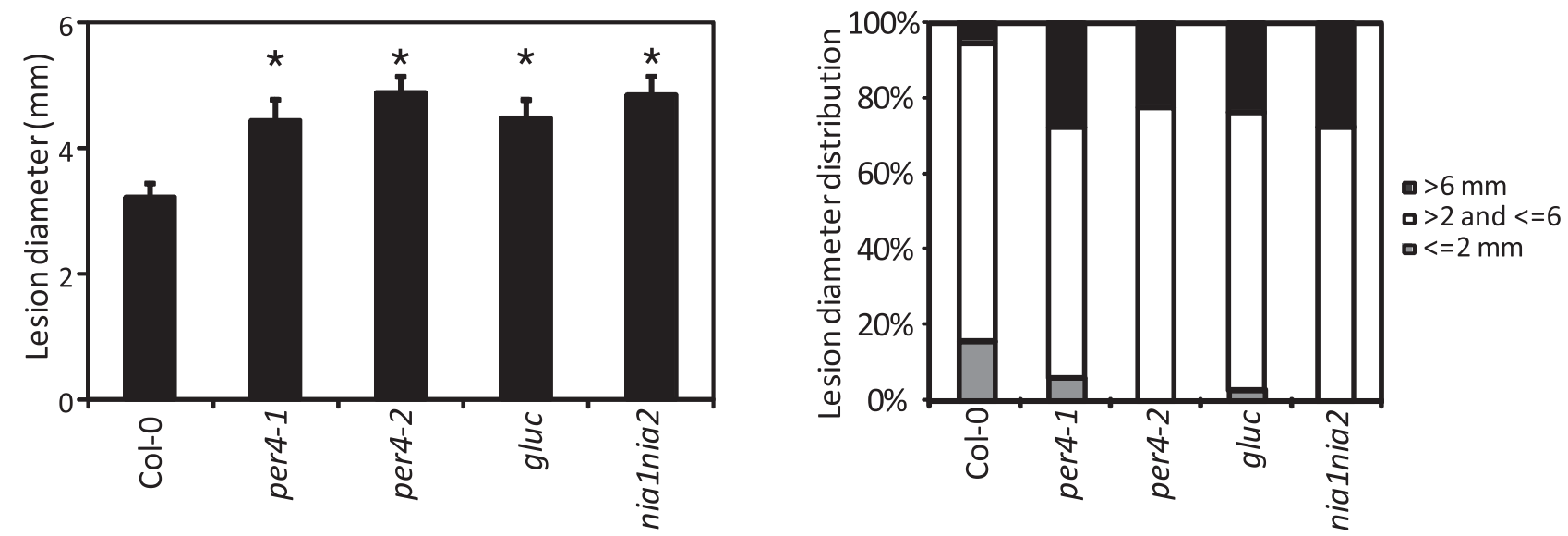

Figure 7. Role of nitric oxide (NO) in basal resistance to Botrytis cinerea. (a) Exogenous application of cPTIO decreases resistance against B. cinerea in Arabidopsis thaliana. Col-0 leaves were infiltrated with different concentration of cPTIO or water and then inoculated with $B$. cinerea spores $\left(6 \mu \mathrm{L}\right.$ droplets; $5 \cdot 10^{4}$ spores $\left.\mathrm{mL}^{-1}\right)$. Lesion diameters were measured $3 \mathrm{~d}$ after inoculation (left panel) and were grouped into three classes according to their sizes, and the percentage of lesion distribution is shown (right panel). Data are the means $( \pm \mathrm{SE})$ of three independent experiments performed on 10 plants for each genotype with four lesions per plant. Asterisks indicate statistically significant differences between wild type (WT) and cPTIO treatment (see Materials and Methods). (b) Basal resistance to B. cinerea in nitrate reductase (nia1nia2), peroxidase 4 (per4-1 and per4-2) and $\beta$-1,3-glucanase (glu) mutant lines. Four-week-old plants were inoculated on leaves with a $6 \mu \mathrm{L}$ droplet $\left(5 \cdot 10^{4}\right.$ spores $\left.\mathrm{mL}^{-1}\right)$ and symptoms were scored $3 \mathrm{~d}$ later (left panel). Lesion diameters were grouped into three classes according to their sizes and the percentage of lesion distribution is shown (right panel). This experiment was performed on 10 plants for each genotype (four inoculations per plant) and was representative of three independent biological experiments. Data are the mean \pm SE. Asterisks indicate statistically significant differences between WT and mutant lines (see Materials and Methods).

NO production in plant tissues and cell suspensions have been developed, each offering not only individual advantages but also disadvantages, including the lack of sensitivity and/or the risk of interference by NO-unrelated molecules (for review, see Mur et al. 2011). To face the risk of misinterpretation, it is recommended to measure NO production using more than one technique. In the present study, NO production was first monitored using the DAF2-based assay. This well-used method is indirect and relies on the measurement of reactive nitrogen species derived from $\mathrm{NO}$ auto-oxidation, notably $\mathrm{N}_{2} \mathrm{O}_{3}$. The possibility that DAF-2 also reacts with NO-unrelated molecules, thus generating compounds having fluorescence emission profiles similar to that of DAF-2T, has been raised in several studies (Mur et al. 2011). In the present investigation, we showed that $\mathrm{OG}$ treatment of leaf discs triggered an increase of fluorescence. This increase was not observed in the presence of the NO scavenger cPTIO, thus supporting the assumption that it is probably related to NO. To further support this hypothesis, NO production was also investigated using the fluorescence probe CuFL. This probe reacts directly with NO, is more sensitive, and was shown to detect NO specifically over other (reactive) species present in biological systems, including not only $\mathrm{H}_{2} \mathrm{O}_{2}$, peroxynitrite and $\mathrm{HNO}$ but also nitrite and nitrate (Lim et al. 2006). We observed that OGs induced a significant rise of CuFL fluorescence in 
leaf discs, this process being sensitive to cPTIO. Therefore, both the DAF-2 and CuFL methods gave consistent results and support the hypothesis that OGs promote NO production in A. thaliana leaf discs.

Our data provide several lines of evidence implicating $\mathrm{NR}$ as a major source for $\mathrm{NO}$ in response to OGs. OG-induced NO production was reduced in the nialnia2 mutant and partly suppressed in wild-type leaf discs treated with the NR inhibitor tungstate. At the biochemical and molecular levels, the NR-dependent NO production was correlated with enhanced NR activity and up-regulation of NIA1 and NIA2 gene expression. Involvement of NR in NO production has been reported in interactions between plants and pathogen/elicitors such as necrotrophic fungal pathogen (Asai et al. 2008; Perchepied et al. 2010), bacteria (Modolo et al. 2006; Oliveira et al. 2009), chitosan (Li et al. 2009) and the elicitin INF1 (Yamamoto-Katou et al. 2006). However, Modolo et al. (2006) demonstrated that this double mutant has much lower L-arginine content in leaves (almost 10 times lower) as compared with wild-type plants, suggesting that Arg-dependent pathway for NO synthesis could be down-regulated in the nialnia2 mutant. We observed that L-arginine supply did not restore NO production in the nialnia2 mutant. This result confirms the previous observations of Oliveira et al. (2009) showing that no significant increase of NO emission was measured in response to inoculation with pathogen in nialnia2 plants treated with L-arginine. Furthermore, it seems to exclude the possibility that the lower level of NO observed in nialnia2 in response to OGs is related to an L-arginine deficiency in the leaves. Induction of NR activity and/or up-regulation of NR genes have also been demonstrated in potato infected by Phytophthora infestans or in A. thaliana infected by Sclerotinia sclerotorium (Yamamoto et al. 2003; Perchepied et al. 2010). Interestingly, coincident NO production and NR activity induction have been also reported in response to other stimuli like cold stress (Zhao et al. 2009; Cantrel et al. 2011), $\mathrm{H}_{2} \mathrm{O}_{2}$ treatment (Wang et al. 2010) or the Verticillium dahliae toxin (VD toxin; Shi \& Li 2008). Thus, our study strengthens the possibility that NR-mediated NO production participates in the mechanisms underlying the plant adaptive response to biotic and abiotic stresses through transcriptional regulation, de novo NR biosynthesis and enzyme activation.

In addition to NR, we provided data suggesting that OG-induced NO synthesis might also involve an L-arginine-dependent process. Indeed, NO production was partially suppressed by the mammalian NOS inhibitor L-NAME. The ability of this compound to reduce NO synthesis, as well as NOS-like activities in plant tissues and cell suspensions, has been widely reported (for review, see Corpas et al. 2011). However, one must be cautious on interpretation based on L-NAME. Firstly, the molecular target(s) of L-NAME are unknown in plants. Secondly, previous studies performed in animal biological models showed that beside NOS, L-NAME could also interact with iron and, accordingly, was reported to inhibit the reduction of ferric cytochrome $\mathrm{C}$ by ferrous iron (Peterson et al.
1992). Thirdly, as discussed by Besson-Bard et al. (2008a), the possibility that this compound could also affect the activities of other L-arginine metabolizing enzyme should not be excluded. Notably, the inhibitory effect of mammalian NOS inhibitors on NO production could be related to their ability to suppress enzyme activities including enzymes related to PA synthesis (such as arginase and arginine decarboxylase) and catabolism (PA oxidases). Because the PAs spermine and spermidine were reported to trigger NO synthesis in A. thaliana (Tun et al. 2006; Wimalasekera et al.2011), the suppression of NO synthesis by mammalian NOS could reflect an inhibition of PA synthesis rather than a direct effect on a putative NOS-like enzyme. We tested the involvement of polyamine oxidases (PAOX) in OG-induced NO synthesis using AtPaox mutants. Compared with Col-0, non-significant modification in NO production was observed, minimizing the involvement of PAs in our biological model (data not shown). Finally, we should not rule out the possibility that L-NAME treatment also triggers metabolic disorders impacting NO synthesis through an unspecific process. The identification of the enzymatic source producing NO from L-arginine and a detailed analysis of the molecular mechanism underlying L-NAME effect, notably on nitrogen metabolism, are therefore priority questions that remained to be answered.

Taken together, basically our results suggest that both a NR-dependent and a L-NAME sensitive pathway could mediate NO production in response to OGs. If both processes are unique sources for NO and act independently, the application of L-NAME in the NR double mutant nia1nia2 is expected to lead to an additive effect, that is a complete inhibition of OG-induced NO production. In contrast, we observed that L-NAME did not further affect the remaining OG-induced NO production in the nialnia2 mutant. Moreover, we observed that L-NAME inhibits OG-induced NR activity but not clearly NR gene expression. These data are intriguing and suggest at least two scenarios. Firstly, based on the likely poor specificity of L-NAME, they strongly favour the hypothesis that NR is the main source for NO in response to OGs and that L-NAME effect on NO synthesis and NR activity could reflect unspecific action of the NOS inhibitor. In this regard, to reduce the risk of misinterpretation of data based on L-NAME, we recommend to potential users of this compound to include controls showing the impacts of L-NAME on NR transcript accumulation and activity. Secondly, based on studies showing that L-NAME inhibits NOS-like activities in plants (Corpas et al. 2011), these results might also suggest that two pathways, that is the L-arginine and NR pathways, are co-involved in NO production and do not work independently: L-NAME-sensitive NO production could affect NR-dependent NO production. Supporting this assumption, two studies reported that NO donors and the NO scavenger cPTIO modulate NR activity in Brassica chinensis and Solanum lycocarpum, thus leading to the hypothesis that NR activity may be self-regulated rapidly by its product NO or by NO produced via other sources (Du et al. 2008; Jin et al. 2009). The effect of NO was shown to be 
dependent on $\mathrm{N}$ concentration (Jin et al. 2009). Based on these data, the authors hypothesized that NO can stimulate NR activity at the post-translational level through a direct interaction or, alternatively, by affecting the activity of proteins involved in NR regulation including protein kinases or phosphatases. However, it cannot be excluded that part of the NO produced by Arg-dependent pathway could be oxidized to nitrite, thus providing substrate for NR-triggered NO synthesis.

Whatever the scenario, using L-NAME and/or approaches to impair NR expression and activity, we were not able to completely suppress OG-induced NO synthesis. In contrast, the NO scavenger cPTIO strongly blocked the production of NO triggered by OGs. Therefore, although we cannot exclude the hypothesis that the remaining NO production is related to a residual NR activity in the nialnia2 mutant or in leaf discs treated with tungstate, these observations suggest the involvement of an alternative route to the NR- and Arg-dependent pathways. This route could be involved in OG-induced accumulation of PLP2 transcripts which appeared cPTIO sensitive but not affected by L-NAME or in the nia1nia2 mutant. Numerous possible sources for NO have been proposed (Neill, Desikan \& Hancock 2003; Planchet et al. 2005; Tun et al. 2008). Apart from NR and a potential L-argininedependent pathway, so far we do not have experimental evidence for the occurrence of another route for NO synthesis (data not shown).

\section{OG-induced NO production depends on $\mathrm{Ca}^{2+}$ influx}

Moscatiello et al. (2006) previously reported that OG effects in A. thaliana cell suspensions are mediated through a $\mathrm{La}^{3+}$-sensitive transient elevations of cytosolic $\mathrm{Ca}^{2+}$. Interestingly, we measured a lower OG-induced NO production in the $d n d 1$ mutant impaired in the expression of the $\mathrm{Ca}^{2+}$ permeable channel $C N G C 2$. The reduced NO production observed in $d n d 1$ suggests a role for $\mathrm{CNGC} 2$ and $\mathrm{Ca}^{2+}$ in the transduction of $\mathrm{OG}$ signal leading to NO production. The inhibition of OG-induced NO production by $\mathrm{La}^{3+}$, a calcium channel blocker, corroborates this conclusion. Interestingly, $\mathrm{La}^{3+}$ did not block in vivo OG-induced $\mathrm{NR}$ activity, allowing us to suggest that calcium influx controls only Arg-dependent NO production (Supporting Information Fig. S6). In support of our findings, CNGC2 and associated $\mathrm{Ca}^{2+}$ influx were shown to act upstream of LPS-induced Arg-dependent NO production in A. thaliana guard cells (Ali et al. 2007). Similarly, pharmacological-based strategies pointed out the importance of $\mathrm{Ca}^{2+}$ influx in elicitortriggered NO production (Courtois et al. 2008). However, the effect of lanthanum on NR activity should be interpreted cautiously: whereas calcium influx is important for NO production, it is also known to contribute to NR inhibition through calcium-dependent protein kinase phosphorylation and binding to 14-3-3 proteins (Buchanan, Gruissem \& Jones 2000 for review). Therefore, the observation that lanthanum did not affect NR activity might also reflect inhibitory role of $\mathrm{Ca}^{2+}$ on NR activity.

\section{NO production modulates AtRBOHD-mediated oxidative burst}

One of the earliest characterized events of defence mechanisms is the oxidative burst corresponding to the generation of ROS including $\mathrm{H}_{2} \mathrm{O}_{2}$ and the superoxide anion, $\mathrm{O}_{2}{ }^{--}$ (Lamb \& Dixon 1997; Wojtaszek, Stobiecki \& Bolwell 1997). There is considerable evidence that the elicitor- and pathogen-induced oxidative bursts in Arabidopsis are mediated by AtRBOH proteins, homolog of the gp91 subunit of mammalian NADPH oxidase (Torres, Dangl \& Jones 2002). Our results show that the OG-induced oxidative burst in $A$. thaliana leaf discs was abolished using DPI and in the AtrbohD mutant (Fig. 5a,c), confirming that plasma membrane NADPH oxidase was responsible for the OG-induced oxidative burst as previously observed by Galletti et al. (2008).

We observed that DAF fluorescence was not significantly affected in AtrbohD mutant indicating that $\mathrm{H}_{2} \mathrm{O}_{2}$ was not sufficient for OG-induced NO generation. This finding diverges from other studies assuming that ROS production acts upstream of NO production. Indeed, $\mathrm{H}_{2} \mathrm{O}_{2}$ was shown to be required for ABA- and UV-B-induced NO production in guard cells of both Vicia faba and A. thaliana (Dong et al. 2005; He et al. 2005; Bright et al. 2006) and for chitosanresponse in Pisum sativum (Srivastava et al. 2009). In contrast, we observed that the application of the cPTIO or L-NAME diminished the oxidative burst in response to OGs (Fig. 5b). Although a direct scavenging of ROS by cPTIO could not be excluded, these data, together with L-NAME effect, suggest a positive role for NO in regulating ROS production. These findings indicate that the induction of $\mathrm{H}_{2} \mathrm{O}_{2}$ accumulation may be a downstream component of OG-induced NO production. These results are in agreement with previous observations made in the context of the interaction between $B$. cinerea and $V$. vinifera which showed that NO, whether produced in response to BcPG1 or released by a NO donor, leads to ROS production in grapevine cells (Vandelle et al. 2006). In contrast, other studies reported that reducing endogenous NO level using cPTIO or plant mutants impaired in inducible NO production (e.g. NR double mutant) enhanced $\mathrm{H}_{2} \mathrm{O}_{2}$ accumulation (Tada et al.2004; Asai et al.2008), suggesting that part of the $\mathrm{O}_{2}{ }^{--}$produced by NADPH oxidase is scavenged by NO. Furthermore, recently Yun et al. (2011) found that NO abolishes AtRBOHD activity through S-nitrosylation.

Importantly, in contrast to cPTIO or L-NAME treatments, we observed that the nia1nia2 mutant behaves like wild-type plants in terms of OG-induced ROS generation, indicating that NR-mediated NO production is not essential for oxidative burst. These data support the hypothesis that NO production might involve at least two enzymatic sources, NO resulting from the Arg-dependent pathway being involved in the control of the oxidative burst. 
However, as discussed above, this interpretation is hindered by the limited specificity of L-NAME.

\section{OG-induced NO-dependent genes are involved in $A$. thaliana basal resistance to $B$. cinerea}

We analysed, using real-time qPCR, transcript accumulation of candidate genes in response to OGs in the presence of cPTIO and L-NAME. The reduced transcript level of PLP2, PER4 and $\beta$-1,3-glucanase observed in leaf discs co-treated with cPTIO or L-NAME and OGs indicates that their expression is, at least partly, dependent on NO. As PER4 and $\beta$-1,3-glucanase genes were also induced by $B$. cinerea, we investigated the role of the corresponding proteins in the resistance to the pathogen using mutant lines. The different mutant lines impaired in PER4 and $\beta$-1,3-glucanase were more susceptible to $B$. cinerea, indicating that PER4 and $\beta$-1,3-glucanase expression is required for $A$.thaliana resistance against $B$. cinerea. Because NO regulates the expression of these genes in response to OGs, these data also suggest that $\mathrm{NO}$ is involved in the processes controlling resistance through gene regulation. Accordingly, a higher susceptibility to $B$. $c i$ nerea was observed for Col-0 plants treated with cPTIO and in the nialnia2 mutant. Importantly, impairment of PER4 and $\beta$-1,3-glucanase expression, as well as the suppression of NO synthesis by cPTIO, had a weak effect on plant resistance to $B$. cinerea. Indeed, disease susceptibility was only increased by $20 \%$ in those genotypes or in cPTIO-cotreated Col0 plants. However, we should mention that plant resistance to necrotrophic pathogens such as $B$. cinerea has a quantitative and complex genetic basis involving probably numerous genes. Indeed, 23 quantitative trait loci (QTL) with significant influence on $B$. cinerea lesion size or camalexin accumulation have been identified in A.thaliana (Rowe \& Kliebenstein 2008).

Our observations corroborate previous studies suggesting a role for $\mathrm{NO}$ in disease resistance to necrotrophic pathogen (Asai \& Yoshioka 2009; Perchepied et al. 2010). Notably, our investigation demonstrates that the effect of endogenously produced NO could be explained by the regulation of genes activated during fungal colonization or elicitor treatment. These genes encode proteins related to plant defence. The anionic peroxidase PER4 is described as a lignin-forming peroxidase putatively located in the endomembrane system. This protein is related to the PR9 family (van Loon, Rep \& Pieterse 2006) and closely similar to prxA3a involved in both lignin content and composition in hybrid aspen ( $\mathrm{Li}$ et al. 2003). PR-9 is a specific type of peroxidase that could act in cell wall reinforcement and then enhance resistance to pathogens. $\beta$-1,3-glucanase is also referred to as a PR protein of the PR2 family (Doxey et al. 2007). This protein, putatively localized in plant cell wall, could affect mycelium growth by hydrolysing the protective glucan sheath on the surface of the fungus such as B. cinerea (Gil-ad, Bar-Nun \& Mayer 2001).

In conclusion, we proposed a role for NO in mediating OG-induced effects in A. thaliana, including ROS

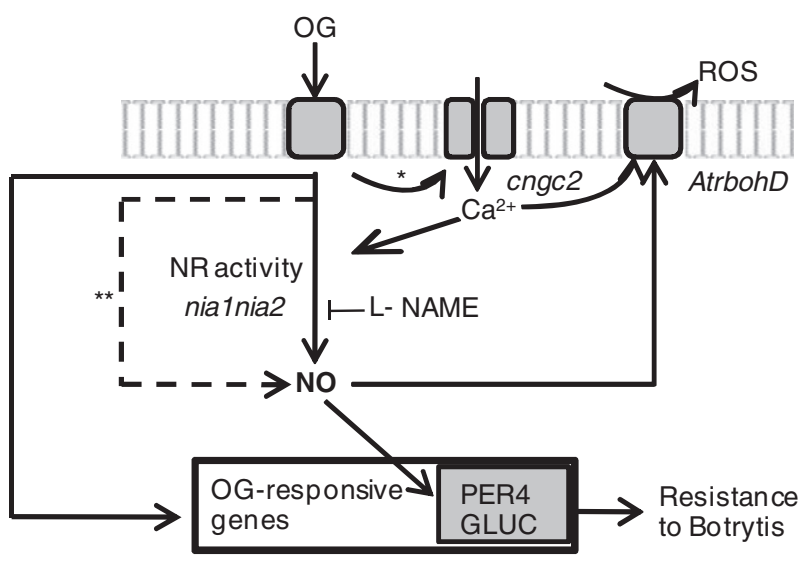

Figure 8. Schematic illustration of the signalling network involving nitric oxide (NO) that modulates oligogalacturonide (OG)-triggered immunity against Botrytis cinerea in Arabidopsis thaliana. NO production involves a nitrate reductase (NR) pathway, sensitive to L-NAME. OG-induced Arg-dependent NO production was $\mathrm{Ca}^{2+}$ dependent and modulated RBOHDmediated reactive oxygen species (ROS) production. NO produced by Arg and NR pathways participates in the regulation of OG-responsive genes such as anionic peroxidase (PER4) and a $\beta$-1,3-glucanase. Mutant plants impaired in PER4 and $\beta$-1,3-glucanase, as well as Col-0 plants treated with the NO scavenger cPTIO, were more susceptible to $B$. cinerea. $(*)$ : OGs elicit a rapid elevation of cytosolic-free calcium in $A$. thaliana cells (Moscatiello et al. 2006). (**): not characterized alternative route for NO production.

production and the expression of genes encoding PER4 and a $\beta$-1,3-glucanase (Fig. 8). The control of the expression of those genes by NO might constitute one of the mechanisms underlying $A$. thaliana basal resistance to $B$. cinerea.

\section{ACKNOWLEDGMENTS}

S.R. was supported by a fellowship from Higher Education Commission, Pakistan. This work was supported by the Agence Nationale de la Recherche (program BLAN072 184783) and the Conseil Régional de Bourgogne (PARIAGRALE 8 project).

\section{REFERENCES}

Akaike T. \& Maeda H. (1996) Quantitation of nitric oxide using 2-phenyl-4,4,5,5-tetramethylimidazoline-1-oxyl 3-oxide (PTIO). Methods in Enzymology 268, 211-221.

Ali R., Ma W., Lemtiri-Chlieh F., Tsaltas D., Leng Q., von Bodman S. \& Berkowitz G.A. (2007) Death don't have no mercy and neither does calcium: Arabidopsis cyclic nucleotide gated channel2 and innate immunity. The Plant Cell 19, 1081-1095.

Arasimowicz M., Floryszak-Wieczorek J., Milczarek G. \& Jelonek T. (2009) Nitric oxide, induced by wounding, mediates redox regulation in pelargonium leaves. Plant Biology 11, 650-663.

Asai S. \& Yoshioka H. (2009) Nitric oxide as a partner of reactive oxygen species participates in disease resistance to necrotrophic pathogen Botrytis cinerea in Nicotiana benthamiana. Molecular Plant-Microbe Interactions 22, 619-629. 
Asai S., Ohta K. \& Yoshioka H. (2008) MAPK signaling regulates nitric oxide and NADPH oxidase-dependent oxidative bursts in Nicotiana benthamiana. The Plant Cell 20, 1390-1406.

Aziz A., Gauthier A., Bézier A., Poinssot B., Joubert J.M., Pugin A., Heyraud A. \& Baillieul F. (2007) Elicitor and resistanceinducing activities of $\beta-1,4$ cellodextrins in grapevine, comparison with $\beta-1,3$ glucans and $\alpha-1,4$ oligogalacturonides. Journal of Experimental Botany 58, 1463-1472.

Besson-Bard A., Pugin A. \& Wendehenne D. (2008a) New insights into nitric oxide signaling in plants. Annual Review of Plant Biology 59, 21-39.

Besson-Bard A., Griveau S., Bedioui F. \& Wendehenne D. (2008b) Real-time electrochemical detection of extracellular nitric oxide in tobacco cells exposed to cryptogein, an elicitor of defence responses. Journal of Experimental Botany 59, 3407-3414.

Besson-Bard A., Astier J., Rasul S., Wawer I., Dubreuil-Maurizi C., Jeandroz S. \& Wendehenne D. (2009) Current view of nitric oxide-responsive genes in plants. Plant Science 177, 302-309.

Bright J., Desikan R., Hancock J.T., Weir I.S. \& Neill S.J. (2006) ABA induced $\mathrm{NO}$ generation and stomatal closure in Arabidopsis are dependent on $\mathrm{H}_{2} \mathrm{O}_{2}$ synthesis. The Plant Journal 45, 113 122.

Buchanan B.B., Gruissem W. \& Jones R.L. (2000) Biochemistry and Molecular Biology of Plants. American Society of Plant Physiologists, Rockville, MD, USA.

Cantrel C., Vazquez T., Puyaubert J., Rezé N., Lesch M., Kaiser W.M., Dutilleul C., Guillas I., Zachowski A. \& Baudouin E. (2011) Nitric oxide participates in cold-responsive phosphosphingolipid formation and gene expression in Arabidopsis thaliana. New Phytologist 189, 415-427.

Cecconi D., Orzetti S., Vandelle E., Rinalducci S., Zolla L. \& Delledonne M. (2009) Protein nitration during defense response in Arabidopsis thaliana. Electrophoresis 30, 2460-2468.

Clarke A., Desikan R., Hurst R.D., Hancock J.T. \& Neill S.J. (2000) NO way back: nitric oxide and programmed cell death in Arabidopsis thaliana suspension cultures. The Plant Journal 24, 667-677.

Corpas F.J., Barroso J.B., Carreras A., Valderrama R., Palma J.M., León A.M., Sandalio L.M. \& del Río L.A. (2006) Constitutive arginine-dependent nitric oxide synthase activity in different organs of pea seedlings during plant development. Planta 224, $246-254$.

Corpas F.J., Leterrier M., Valderrama R., Airaki M., Chaki M., Palma J.M. \& Barroso J.B. (2011) Nitric oxide imbalance provokes a nitrosative response in plants under abiotic stress. Plant Science 181, 604-611.

Courtois C., Besson A., Dahan J., Bourque S., Dobrowolska G., Pugin A. \& Wendehenne D. (2008) Nitric oxide signalling in plants: interplays with $\mathrm{Ca}^{2+}$ and protein kinases. Journal of Experimental Botany 59, 155-163.

Cueto M., Hernández-Perera O., Martín R., Bentura M.L., Rodrigo J., Lamas S. \& Golvano M.P. (1996) Presence of nitric oxide synthase activity in roots and nodules of Lupinus albus. FEBS Letters 398, 159-164.

Delledonne M., Xia Y., Dixon R.A. \& Lamb C. (1998) Nitric oxide functions as a signal in plant disease resistance. Nature 394, $585-588$.

Desikan R., Griffiths R., Hancock J. \& Neill S. (2002) A new role for an old enzyme: nitrate reductase-mediated nitric oxide generation is required for abscisic acid-induced stomatal closure in Arabidopsis thaliana. Proceedings of the National Academy of Sciences of the United States of America 9, 16314-16318.

Dong L.Z.X., Jiang J., An G.Y., Zhang L.R. \& Song C.P. (2005) NO may function in the downstream of $\mathrm{H}_{2} \mathrm{O}_{2}$ in ABA-induced stomatal closure in Vicia faba L. Journal of Plant Physiology and Molecular Biology 31, 62-70.
Dordas C., Hasinoff B.B., Rivoal J. \& Hill R.D. (2004) Class-1 hemoglobins, nitrate and NO levels in anoxic maize cellsuspension cultures. Planta 219, 66-72.

Doxey A.C., Yaish M.W.F., Moffatt B.A., Griffith M. \& McConkey B.J. (2007) Functional divergence in the Arabidopsis $\beta-1,3$-glucanase gene family inferred by phylogenetic reconstruction of expression states. Molecular Biology and Evolution 24, 1045-1055.

Du S., Zhang Y., Lin X., Wang Y. \& Tang C. (2008) Regulation of nitrate reductase by nitric oxide in Chinese cabbage pakchoi (Brassica chinensis L. Plant, Cell \& Environment 31, 195-204.

Dubreuil-Maurizi C., Vitecek J., Marty L., Branciard L., Frettinger P., Wendehenne D., Meyer A.J., Mauch F. \& Poinssot B. (2011) Glutathione deficiency of the Arabidopsis mutant pad2-1 affects oxidative stress-related events, defense gene expression and hypersensitive response. Plant Physiology 157, 2000-2012.

Durner J., Wendehenne D. \& Klessig D.F. (1998) Defense gene induction in tobacco by nitric oxide, cyclic GMP and cyclic ADP ribose. Proceedings of the National Academy of Sciences of the United States of America 95, 10328-10333.

Ferrari S., Galletti R., Denoux C., De Lorenzo G., Ausubel F.M. \& Dewdney J. (2007) Resistance to Botrytis cinerea induced in Arabidopsis by elicitors is independent of salicylic acid, ethylene, or jasmonate signaling but requires PHYTOALEXIN DEFICIENT3. Plant Physiology 144, 367-379.

Floryszak Wieczorek J., Arasimowicz M., Milczarek G., Jelen H. \& Jackowiak H. (2007) Only an early nitric oxide burst and the following wave of secondary nitric oxide generation enhanced effective defence responses of pelargonium to a necrotrophic pathogen. New Phytologist 175, 718-730.

Foissner I., Wendehenne D., Langebartels C. \& Durner J. (2000) In vivo imaging of an elicitor induced nitric oxide burst in tobacco. The Plant Journal 23, 817-824.

Galletti R., Denoux C., Gambetta S., Dewdney J., Ausubel F.M., De Lorenzo G. \& Ferrari S. (2008) The AtrbohD-mediated oxidative burst elicited by oligogalacturonides in Arabidopsis is dispensable for the activation of defense responses effective against Botrytis cinerea. Plant Physiology 148, 1695-1706.

Gil-ad N.L., Bar-Nun N. \& Mayer A.M. (2001) The possible function of the glucan sheath of Botrytis cinerea: effects on the distribution of enzyme activities. FEMS Microbiology Letters 199, 109-113.

Hahn M.G., Darvill A.G. \& Albersheim P. (2001) Host-pathogen interactions. XIX. The endogenous elicitor, a fragment of plant cell wall polysaccharide that elicits phytoalexin accumulation in soy beans. Plant Physiology 68, 1161-1169.

He J.M., Xu H., She X.P., Song X.G. \& Zhao W.M. (2005) The role and the interrelationship of hydrogen peroxide and nitric oxide in the UV-B-induced stomatal closure in broad bean. Functional Plant Biology 32, 237-247.

Horchani F., Prevot M., Boscari A., et al. (2011) Both plant and bacterial nitrate reductases contribute to nitric oxide production in Medicago truncatula nitrogen-fixing nodules. Plant Physiology 155, 1023-1036.

Jin G.H., Lee D.Y., Cheon Y.J., Gim H.J., Kim D.H., Kim H.D., Ryu J.H. \& Jeon R. (2009) Synthesis of phenylisothiourea derivatives as inhibitors of NO production in LPS activated macrophages. Bioorganic and Medicinal Chemistry Letters 19, 30883092 .

Jourd'heuil D. (2002) Increased nitric oxide-dependent nitrosylation of 4, 5-diaminofluorescein by oxidants: implications for the measurement of intracellular nitric oxide. Free Radical Biology and Medicine 33, 676-684.

Keppler L.D., Baker C.J. \& Atkinson M.M. (1989) Active oxygen production during a bacteria-induced hypersensitive reaction in tobacco suspension cells. Phytopathology 79, 974-978. 
La Camera S., Geoffroy P., Samaha H., Ndiaye A., Rahim G., Legrand M. \& Heitz T. (2005) A pathogen inducible patatin like lipid acyl hydrolase facilitates fungal and bacterial host colonization in Arabidopsis. The Plant Journal 44, 810-825.

Lamb C. \& Dixon R.A. (1997) The oxidative burst in plant disease resistance. Annual Review of Plant Physiology and Plant Molecular Biology 48, 251-275.

Leitner M., Vandelle E., Gaupels F., Bellin D. \& Delledonne M. (2009) NO signals in the haze: nitric oxide signalling in plant defence. Current Opinion in Plant Biology 12, 451-458.

Li Y., Kajita S., Kawai S., Katayama Y. \& Morohoshi N. (2003) Down-regulation of an anionic peroxidase in transgenic aspen and its effect on lignin characteristics. Journal of Plant Research 116, 175-182.

Li Y., Yin H., Wang Q., Zhao X., Du Y. \& Li F. (2009) Oligochitosan induced Brassica napus L. production of $\mathrm{NO}$ and $\mathrm{H}_{2} \mathrm{O}_{2}$ and their physiological function. Carbohydrate Polymers 75, 612 617.

Lim M.H., Xu D. \& Lippard S.J. (2006) Visualization of nitric oxide in living cells by a copper based fluorescent probe. Nature Chemical Biology 2, 375-380.

Livak K.J. \& Schmittgen T.D. (2001) Analysis of relative gene expression data using real-time quantitative PCR and the $2^{-\triangle \triangle C T}$ method. Methods 25, 402-408.

Modolo L.V., Cunha F.Q., Braga M.R. \& Salgado I. (2002) Nitric oxide synthase-mediated phytoalexin accumulation in soybean cotyledons in response to the Diaporthe phaseolorum f. sp. meridionalis elicitor. Plant Physiology 130, 1288-1297.

Modolo L.V., Augusto O., Almeida I.M.G., Pinto-Maglio C.A.F., Oliveira H.C., Seligman K. \& Salgado I. (2006) Decreased arginine and nitrite levels in nitrate reductase-deficient Arabidopsis thaliana plants impair nitric oxide synthesis and the hypersensitive response to Pseudomonas syringae. Plant Science 171, 34-40.

Moscatiello R., Mariani P., Sanders D. \& Maathuis F.J.M. (2006) Transcriptional analysis of calcium-independent signalling pathways induced by oligogalacturonides. Journal of Experimental Botany 57, 2847-2865.

Mur L.A.J., Mandon J., Cristescu S.M., Harren F.J.M. \& Prats E. (2011) Methods of nitric oxide detection in plants: a commentary. Plant Science 181, 509-519.

Neill S.J., Desikan R. \& Hancock J.T. (2003) Nitric oxide signalling in plants. New Phytologist 159, 11-35.

Oliveira H.C., Justino G.C., Sodek L. \& Salgado I. (2009) Amino acid recovery does not prevent susceptibility to Pseudomonas syringae in nitrate reductase double-deficient Arabidopsis thaliana plants. Plant Science 176, 105-111.

Perchepied L., Balagué C., Riou C., Claudel-Renard C., Rivière N., Grezes-Besset B. \& Roby D. (2010) Nitric oxide participates in the complex interplay of defense-related signaling pathways controlling disease resistance to Sclerotinia sclerotiorum in Arabidopsis thaliana. Molecular Plant-Microbe Interactions 23, 846-860.

Peterson D.A., Peterson D.C., Archer S. \& Weir E.K. (1992) The non-specificity of specific nitric oxide synthase inhibitors. Biochemical and Biophysical Research Communications 187, 797-801.

Piterkova J., Pet Ivalsky M., Luhova L., Mieslerova B., Sedla Ova M. \& Lebeda A. (2009) Local and systemic production of nitric oxide in tomato responses to powdery mildew infection. Molecular Plant Pathology 10, 501-513.

Planchet E., Jagadis Gupta K., Sonoda M. \& Kaiser W.M. (2005) Nitric oxide emission from tobacco leaves and cell suspensions: rate limiting factors and evidence for the involvement of mitochondrial electron transport. The Plant Journal 41, 732743.
Planchet E. \& Kaiser W.M. (2006) Nitric oxide (NO) detection by DAF fluorescence and chemiluminescence: a comparison using abiotic and biotic NO sources. Journal of Experimental Botany 57, 3043-3055.

del Río L.A., Javier Corpas F. \& Barroso J.B. (2004) Nitric oxide and nitric oxide synthase activity in plants. Phytochemistry $\mathbf{6 5}$, 783-792.

Rowe H.C. \& Kliebenstein D.J. (2008) Complex genetics control natural variation in Arabidopsis thaliana resistance to Botrytis cinerea. Genetics 180, 2237-2250.

Sakihama Y., Nakamura S. \& Yamasaki H. (2002) Nitric oxide production mediated by nitrate reductase in the green alga Chlamydomonas reinhardtii: an alternative NO production pathway in photosynthetic organisms. Plant and Cell Physiology 43, 290-297.

Shi F.M. \& Li Y.Z. (2008) Verticillium dahliae toxins-induced nitric oxide production in Arabidopsis is major dependent on nitrate reductase. Biochemistry and Molecular Biology Reports 41, $79-85$.

Srivastava N., Gonugunta V.K., Puli M.R. \& Raghavendra A.S. (2009) Nitric oxide production occurs downstream of reactive oxygen species in guard cells during stomatal closure induced by chitosan in abaxial epidermis of Pisum sativum. Planta 229, 757765 .

Tada Y., Mori T., Shinogi T., Yao N., Takahashi S., Betsuyaku S., Sakamoto M., Park P., Nakayashiki H. \& Tosa Y. (2004) Nitric oxide and reactive oxygen species do not elicit hypersensitive cell death but induce apoptosis in the adjacent cells during the defense response of oat. Molecular Plant-Microbe Interactions 17, 245-253.

Ten Have A., Mulder W., Visser J. \& van Kan J.A. (1998) The endopolygalacturonase gene $\mathrm{BcPg} 1$ is required for full virulence of Botrytis cinerea. Molecular Plant-Microbe Interactions 11, 1009-1016.

Torreilles J. (2001) Nitric oxide: one of the more conserved and widespread signaling molecules. Frontiers in Bioscience 1, 11611172.

Torres M.A., Dangl J.L. \& Jones J.D.G. (2002) Arabidopsis gp91 ${ }^{\text {phox }}$ homologues AtrbohD and AtrbohF are required for accumulation of reactive oxygen intermediates in the plant defense response. Proceedings of the National Academy of Sciences of the United States of America 99, 517-522.

Tun N.N., Santa-Catarina C., Begum T., Silveira V., Handro W., Floh E.I.S. \& Scherer G.F.E. (2006) Polyamines induce rapid biosynthesis of nitric oxide (NO) in Arabidopsis thaliana seedlings. Plant and Cell Physiology 47, 346-354.

Tun N.N., Livaja M., Kieber J.J. \& Scherer G.F.E. (2008) Zeatin induced nitric oxide (NO) biosynthesis in Arabidopsis thaliana mutants of NO biosynthesis and of two component signaling genes. New Phytologist 178, 515-531.

Van Loon L.C., Rep M. \& Pieterse C.M.J. (2006) Significance of inducible defense-related proteins in infected plants. Annual Review of Phytopathology 44, 135-162.

Vandelle E. \& Delledonne M. (2008) Methods for nitric oxide detection during plant-pathogen interactions. Methods in Enzymology 437, 575-594.

Vandelle E., Poinssot B., Wendehenne D., Bentejac M. \& Alain P. (2006) Integrated signaling network involving calcium, nitric oxide, and active oxygen species but not mitogen-activated protein kinases in BcPG1-elicited grapevine defenses. Molecular Plant-Microbe Interactions 19, 429-440.

Wang Y., Ries A., Wu K., Yang A. \& Crawford N.M. (2010) The Arabidopsis prohibitin gene PHB3 functions in nitric oxide-mediated responses and in hydrogen peroxideinduced nitric oxide accumulation. The Plant Cell 22, 249259. 
Wilkinson J.Q. \& Crawford N.M. (1991) Identification of the Arabidopsis CHL3 gene as the nitrate reductase structural gene NIA2. The Plant Cell 3, 461-471.

Wimalasekera R., Villar C., Begum T. \& Scherer G.F.E. (2011) COPPER AMINE OXIDASE1 (CuAO1) of Arabidopsis thaliana contributes to abscisic acid- and polyamine-induced nitric oxide biosynthesis and abscisic acid signal transduction. Molecular Plant 4, 663-678.

Wojtaszek P., Stobiecki M. \& Bolwell G.P. (1997) Changes in the composition of exocellular proteins of suspension-cultured Lupinus albus cells in response to fungal elicitors or $\mathrm{CuCl}_{2}$. Journal of Experimental Botany 48, 2015-2021.

Yamamoto A., Katou S., Yoshioka H., Doke N. \& Kawakita K. (2003) Nitrate reductase, a nitric oxide-producing enzyme: induction by pathogen signals. Journal of General Plant Pathology 69, 218-229.

Yamamoto-Katou A., Katou S., Yoshioka H., Doke N. \& Kawakita K. (2006) Nitrate reductase is responsible for elicitin-induced nitric oxide production in Nicotiana benthamiana. Plant and Cell Physiology 47, 726-735.

Yamasaki H. (2000) Nitrite-dependent nitric oxide production pathway: implications for involvement of active nitrogen species in photoinhibition in vivo. Philosophical Transactions of the Royal Society of London. Series B, Biological Sciences 355, 1477-1488.

Yu X., Sukumaran S. \& Marton L. (1998) Differential expression of the Arabidopsis Nia1 and Nia2 genes. Cytokinin-induced nitrate reductase activity is correlated with increased Nia1 transcription and mRNA levels. Plant Physiology 116, 1091-1096.

Yun B.W., Feechan A., Yin M., et al. (2011) S-nitrosylation of NADPH oxidase regulates cell death in plant immunity. Nature 478, 264-268.

Zaninotto F., Camera S.L., Polverari A. \& Delledonne M. (2006) Cross talk between reactive nitrogen and oxygen species during the hypersensitive disease resistance response. Plant Physiology 141, 379-383.

Zeidler D., Zahringer U., Gerber I., Dubery I., Hartung T., Bors W., Hutzler P. \& Durner J. (2004) Innate immunity in Arabidopsis thaliana: lipopolysaccharides activate nitric oxide synthase (NOS) and induce defense genes. Proceedings of the National Academy of Sciences of the United States of America 101, 1581115816.

Zhao J., Connorton J.M., Guo Y., Li X., Shigaki T., Hirschi K.D. \& Pittman J.K. (2009) Functional studies of split Arabidopsis $\mathrm{Ca}^{2+} / \mathrm{H}^{+}$exchangers. Journal of Biological Chemistry 284, 34075 34083 .

Zimmerli L., Metraux J.P. \& Mauch-Mani B. (2001) $\beta$ Aminobutyric acid-induced protection of Arabidopsis against the necrotrophic fungus Botrytis cinerea. Plant Physiology 126, 517-523.

Zottini M., Costa A., De Michele R., Ruzzene M., Carimi F. \& Lo Schiavo F. (2007) Salicylic acid activates nitric oxide synthesis in Arabidopsis. Journal of Experimental Botany 58, 1397-1405.

Received 3 May 2011; received in revised form 7 February 2012; accepted for publication 20 February 2012

\section{SUPPORTING INFORMATION}

Additional Supporting Information may be found in the online version of this article:

Figure S1. Comparative analysis of NO detection using DAF-2 and CuFL fluorescent probes. The DAF-2 probe was added at a final concentration of $5 \mu \mathrm{M}$ in $200 \mu \mathrm{L}$ Tris- $\mathrm{HCl}$ (50 mu, pH 7.5). The CuFL probe (Strem Chemicals,
Bischheim, France) was freshly prepared by adding 1:1 FL solution $(1.0 \mathrm{~mm})$ to the copper (II) solution $(1.0 \mathrm{~mm})$ and added at a final concentration of $5 \mu \mathrm{M}$ in $200 \mu \mathrm{L}$ Tris- $\mathrm{HCl}$ (10 mm, pH 7.5) KCl (10 mm). The increase of fluorescence triggered by GSNO $(200 \mu \mathrm{M})$ was measured using a spectrofluorometer (Mithras, Berthold Technologies, Germany) with a $485 \mathrm{~nm}$ excitation and a $535 \mathrm{~nm}$ emission filters. A second addition of GSNO $(200 \mu \mathrm{M})$ was performed after $120 \mathrm{~min}$ (arrows). Fluorescence was expressed as relative fluorescence units (arbitrary units: au) after subtracting background fluorescence of time zero (t0) and of the corresponding control (probe without GSNO). This experiment is representative of 3 independent experiments.

Figure S2. NO detection in $A$. thaliana leaf discs by $\mathrm{CuFL}$ probe. NO production was monitored after 1 hour of treatment in the absence (control) or presence of OGs $\left(2.5 \mathrm{mg} \cdot \mathrm{mL}^{-1}\right)$, with or without NO scavenger (cPTIO $500 \mu \mathrm{M}$ ). Each value represents the mean of 8 measurements $\pm \mathrm{SD}$. Leaf discs excised from plants were infiltrated under vacuum for $3 \mathrm{~min}$ with an aqueous solution of OGs. For control treatment, OGs were replaced by an equivalent volume of water. After infiltration, discs were incubated for one hour with respective solutions and then each disc was put in separate well of 96 well plates (Microtest flatbottom, Becton Dickinson, Europe) in $200 \mu \mathrm{L}$ Tris- $\mathrm{HCl}(10 \mathrm{~mm}, \mathrm{pH} 7.5) \mathrm{KCl}(10 \mathrm{~mm})$. The CuFL probe (Strem Chemicals, Bischheim, France) was freshly prepared by adding 1:1 FL solution $(1.0 \mathrm{~mm})$ to the copper (II) solution (1.0 mM) and added in each well (final concentration of $5 \mu \mathrm{M}$ ). The increase of fluorescence triggered by OGs was measured using a spectrofluorometer (Mithras, Berthold Technologies, Germany) with a $485 \mathrm{~nm}$ excitation and a $535 \mathrm{~nm}$ emission filter. Fluorescence was expressed as relative fluorescence units (arbitrary units: au) after subtracting background fluorescence of time zero ( $\mathrm{t} 0$ ). This experiment is representative of 3 independent experiments using independent biological material.

Figure S3. Effect of L-NAME (a) or tungstate (b) on OG-induced NO production in Col-0 leaf discs. NO production was monitored as described in Fig. 1 and visualized in the first 3 hours of treatment after subtracting fluorescence of corresponding control. Each value represents the mean of 8 measurements. This experiment is representative of at least 3 independent experiments using independent biological material.

Figure S4. $P L P 2$ transcript accumulation in response to OGs in the nia1nia2 double mutant. Col-0 and nialnia2 leaf discs were infiltrated with water or OGs $\left(2.5 \mathrm{mg} \cdot \mathrm{mL}^{-1}\right)$ and harvested for analysis after different time intervals. Bars indicate average expression $( \pm \mathrm{SD})$ of three biological replicates.

Figure S5. Effect of cPTIO on Botrytis cinerea growth. Botrytis cinerea strain BMM (Zimmerli et al. 2000) was grown on Petri plates containing PDA (potato dextrose agar, DIFCO) for 10-12 days. Spores were harvested in water and were quantified under a microscope. To verify the effect of cPTIO on B. cinerea growth, spores were diluted to obtain the final concentration of $5 \times 10^{4}$ spores $\mathrm{mL}^{-1} .12 \mu \mathrm{L}$ 
of spore suspension $\left(5 \times 10^{4}\right.$ spores $\left.\mathrm{mL}^{-1}\right)$ with $\mathrm{cPTIO}$ or water in $\mathrm{PDB}$ medium was placed on glass slides and allowed to grow under high humidity for different time. Fungal growth was observed under microscope.

Figure S6. Effect of cPTIO treatment on transcript accumulation of NR genes. Col-0 leaf discs were infiltrated with water or OGs $\left(2.5 \mathrm{mg} \cdot \mathrm{mL}^{-1}\right)$ in the presence or absence of L-NAME ( $5 \mathrm{~mm}$ ) and harvested for analysis after different time intervals. Transcribed mRNAs were analysed by real-time quantitative RT-PCR. Levels of transcripts were calculated using $2^{-\Delta \Delta C T}$ method. This experiment is representative of 2 independent experiments using independent biological material.
Figure S7. In vitro NR activity in wild-type (Col-0) leaf discs treated with water (control), OGs/OGs + lanthanum (5 mM) and in nialnia2 NR mutant. Each value represents the mean $\pm \mathrm{SE}$ of three independent experiments performed using independent biological materials.

Please note: Wiley-Blackwell are not responsible for the content or functionality of any supporting materials supplied by the authors. Any queries (other than missing material) should be directed to the corresponding author for the article. 